\title{
Portfolio rebalancing in times of stress
}

Andreas M. Fischer, Rafael Greminger and Christian Grisse

SNB Working Papers

$11 / 2017$ 


\section{DISCLAIMER}

The views expressed in this paper are those of the author(s) and do not necessarily represent those of the Swiss National Bank. Working Papers describe research in progress. Their aim is to elicit comments and to further debate.

\section{COPYRIGHT $\odot$}

The Swiss National Bank (SNB) respects all third-party rights, in particular rights relating to works protected by copyright (information or data, wordings and depictions, to the extent that these are of an individual character).

SNB publications containing a reference to a copyright (@) Swiss National Bank/SNB, Zurich/year, or similar) may, under copyright law, only be used (reproduced, used via the internet, etc.) for non-commercial purposes and provided that the source is mentioned. Their use for commercial purposes is only permitted with the prior express consent of the SNB.

General information and data published without reference to a copyright may be used without mentioning the source. To the extent that the information and data clearly derive from outside sources, the users of such information and data are obliged to respect any existing copyrights and to obtain the right of use from the relevant outside source themselves.

\section{LIMITATION OF LIABILITY}

The SNB accepts no responsibility for any information it provides. Under no circumstances will it accept any liability for losses or damage which may result from the use of such information. This limitation of liability applies, in particular, to the topicality, accuracy, validity and availability of the information.

ISSN 1660-7716 (printed version)

ISSN 1660-7724 (online version)

(C) 2017 by Swiss National Bank, Börsenstrasse 15,

P.O. Box, $\mathrm{CH}-8022$ Zurich 


\title{
Portfolio rebalancing in times of stress*
}

\author{
Andreas M. Fischer \\ Swiss National Bank and CEPR
}

\author{
Rafael Greminger \\ Tilburg University
}

Christian Grisse

Swiss National Bank

This version: June 2017

\begin{abstract}
This paper investigates time variation in the dynamics of international portfolio equity flows. We extend the empirical model of Hau and Rey (2004) by embedding a two-state Markov regime-switching model into the structural VAR. The model is estimated using monthly data for the period 1995-2015 on equity returns, exchange rate returns and equity flows between the United States and advanced and emerging economies. We find that the data are consistent with portfolio rebalancing. The estimated states match periods of low and high financial stress. Our main result is that for equity flows between the United States and emerging markets, the rebalancing dynamics differ between high and low episodes of financial stress. A switch from the low to the high stress regime is associated with capital outflows from emerging markets. Once in the high stress regime, the response of capital flows to exchange rate shocks is smaller than in normal (low stress) periods.
\end{abstract}

JEL classification: F30, G11, G15

Keywords: Portfolio rebalancing, equity flows, exchange rates, financial stress, structural VAR, sign restrictions, regime switching

${ }^{*}$ Contact: andreas.fischer@snb.ch, r.p.greminger@tilburguniversity.edu,christian.grisse@snb.ch. We would like to thank Pierre-Oliver Gourinchas, Sylvia Kaufmann, Hélène Rey, and an anonymous referee of the SNB working paper series for helpful comments and suggestions, as well as participants at an SNB brownbag seminar, the University of Michigan, the 2017 BIS-SNB research workshop, and the 2017 annual meeting of the Swiss Society for Economics and Statistics for their comments. The views expressed are those of the authors and do not necessarily reflect the position of the Swiss National Bank. 


\section{Introduction}

According to theoretical models of portfolio rebalancing, global investors allocate their portfolio by balancing the expected risk and return of assets across international markets. When price shocks cause the portfolio weights to deviate from their optimal risk-return maximizing values, investors rebalance their portfolios. This portfolio rebalancing - also labeled negative feedback trading or contrarian investment - induces stabilizing dynamics. As an example, consider a random shock associated with an exchange rate appreciation in some foreign country. Assuming global investors' exchange rate exposure is not perfectly hedged, this shock increases the portfolio share of that country's equities above its desired level. ${ }^{1}$ To restore the optimal risk-return tradeoff, investors sell equities from the respective foreign equity market. These asset sales trigger equity outflows that mitigate the initial currency appreciation.

A large empirical literature establishes that portfolio rebalancing is important in practice. ${ }^{2}$ Curcuru et al. (2011) find that international U.S. equity investment exhibits partial rebalancing, as investors sell stocks that have recently performed well. Hau and Rey (2004) impose the sign restrictions implied by portfolio rebalancing in a structural VAR of equity flows, equity returns and exchange rate returns and find that the dynamics of equity flows between the United States and four advanced economies are consistent with rebalancing. Hau and Rey (2006) develop an equilibrium model of rebalancing and find that the model's predictions are supported by the data.

Portfolio managers rebalance either periodically (i.e., monthly or quarterly) or in response to major events, such as currency crises or stock market crashes, in which pre-established parameter thresholds are breached. These two strategies for re-assessing the risk-return tradeoff for portfolios suggest that the aggregate response of capital flows to price shocks may strongly differ between high and low financial stress periods. Although the international finance literature on portfolio rebalancing typically assumes that the response of portfolio equity flows to asset price shocks is time invariant and that it exhibits stabilizing behavior, there is considerable evidence that shortterm-oriented equity outflows, including portfolio equity flows, are subject to sudden reversals, with foreign investments repatriated during periods of high financial stress. The dynamics of equity flows in response to financial crises are frequently viewed to be destabilizing. The extreme case of sudden

\footnotetext{
${ }^{1}$ International risk sharing requires a portfolio share in line with the world market portfolio. However, for home investors, foreign currency investments are associated with exchange rate risk. If markets are incomplete, such that exchange rate risk cannot be fully eliminated, this induces home bias in portfolios and rebalancing in response to exchange rate shocks.

${ }^{2}$ Large institutional investors, such as the Norwegian oil fund (see Ang et al. 2014), rebalance their portfolio following valuation changes towards pre-decided weights. Rau (2009) finds evidence of partial rebalancing among small- and medium-sized defined benefit pension plans. Blake et al. (1999) document that the portfolio weights of UK pension funds exhibit slow mean reversion towards the strategic asset allocation, while Bikker et al. (2010) and De Haan and Kakes (2011) find that Dutch pension funds and insurance companies tend to be contrarian traders. Evidence against rebalancing is provided by Radatz and Schmukler (2012). They find that investors pull out of mutual funds in times of stress, and in turn, fund managers move out of stressed countries. Thus, mutual funds act in a destabilizing way and transmit shocks.
} 
stops, a sharp slowdown in private capital inflows into emerging market economies, frequently threatens a country's financial system and results in a deterioration in output and an exchange rate depreciation. ${ }^{3}$

In this paper, we examine whether the dynamics of international equity flows induced by portfolio rebalancing are time varying. We extend the structural VAR framework used in Hau and Rey (2004), identified using sign restrictions, by allowing time-varying dynamics. To do so, we embed a two-state Markov regime-switching model into the structural VAR. Allowing time-varying behavior in this way introduces greater realism to a shock process driven by events such as global financial crises. The model is estimated by using monthly data (1995-2015) on equity returns, exchange rate returns and equity flows between the United States and a set of advanced and emerging economies. Our results provide insights on the following questions that are highly relevant to policymakers considering financial stability issues linked to international capital flows in different environments of uncertainty: Do the stabilizing dynamics of portfolio rebalancing differ between high and low levels of financial stress? How does the response of equity flows to asset price shocks differ between emerging market economies and advanced countries? To the best of our knowledge, this paper is the first to consider how equity flows respond to price shocks in a regime-dependent setting.

We find that the dynamics of equity returns, exchange rate returns and equity flows between the United States and emerging markets are consistent with portfolio rebalancing. ${ }^{4}$ The timing of switches between the two states matches periods of low and high financial stress, with periods of high stress corresponding to a Markov state with low persistence. Our main empirical result is that for equity flows between the United States and emerging markets, the dynamics induced by rebalancing differ between high and low financial stress episodes. A switch from the low to the high stress regime is associated with capital outflows from emerging markets. Once in the high stress regime, the response of capital flows to exchange rate shocks is smaller than in normal, low stress periods. These empirical findings accord well with the IMF's policy prescription, see Ostry et al. (2011) and Ostry et al. (2010), that emerging market economies may need to impose capital controls or other policy instruments to safeguard their financial system from sudden surges in capital inflows. In contrast to our results for emerging market economies, we find little difference in the dynamics between low and high stress periods for capital flows between the United States and advanced economies.

The empirical results contribute to several strands of the international finance literature. First, the empirical finding that the dynamics induced by portfolio rebalancing are interrupted by switches

\footnotetext{
${ }^{3}$ The literature on sudden stop crises is vast. See Calvo (1998), Calvo and Reinhart (2000), Calvo et al. (2004), Dornbusch and Werner (1994), Dornbusch et al. (1995), and Reinhart and Reinhart (2009).

${ }^{4}$ Following Hau and Rey (2004), our identification structure imposes sign restrictions on the contemporaneous impulse responses that are implied by theoretical models of portfolio rebalancing. The data are consistent with portfolio rebalancing in the sense that we are able to find impulse responses that satisfy the identification restrictions. If portfolio rebalancing did not adequately describe the data, then we would either not find any responses satisfying the restrictions or find that the impulse responses show up with all values very close to zero.
} 
between high and low stress regimes for emerging market economies fits the stylized facts reported in the literature on capital flow reversals. Forbes and Warnock (2012), Reinhart and Reinhart (2009), Hutchison and Noy (2006) and others argue that capital inflows to emerging market economies are subject to sudden stops during financial crises. Second, our empirical finding that the dynamics of portfolio rebalancing are muted during periods of high financial stress is also consistent with the liquidity pull-back hypothesis of Fecht and Gruber (2012) and Nyborg and Ostberg (2014). These studies emphasize the view that investors seek to reduce their exposure to equity in times of stress. Investors have a clear preference for liquid and safe assets during periods of high financial uncertainty. Third, the empirical patterns of international equity returns, equity portfolio flows, and exchange rate returns shown in Hau and Rey (2004) have motivated other studies to consider the dynamics of alternative assets and capital flows. For example, Gyntelberg et al. (2014) use daily data on FX transactions and equity flows for Thailand to provide evidence that portfolio rebalancing is an important determinant of exchange rates. Using the same empirical approach as Hau and Rey (2004) and data on equity portfolio flows into emerging market-dedicated mutual funds, Ehlers and Takáts (2013) similarly find evidence in favor of portfolio rebalancing for equity investment in emerging markets. Breedon and Vitale (2010) find that order flow is correlated with exchange rate movements and that this effect is mainly due to portfolio balance rather than information effects. However, these studies do not consider the possibility that the dynamics of these financial variables may change when financial uncertainty is high.

The remainder of this paper is organized as follows. Section 2 presents the theoretical explanation for why portfolio rebalancing dynamics may vary between low and high financial stress periods. Section 3 presents the structural VAR model with two-state Markov switching and the identification strategy. Section 4 discusses the data and reports their statistical properties. Section 5 presents the main results in the form of impulse responses. Section 6 discusses several robustness checks. Section 7 concludes.

\section{Theoretical motivation}

In this section, we argue that the dynamics of capital flows, exchange rates and equity returns are likely to change in periods of high financial stress. First, standard asset pricing models suggest that the response of capital flows to returns induced by portfolio rebalancing is smaller in periods of financial stress. Second, the effect of a given capital flow on returns is likely to increase in times of stress.

\subsection{Time variation in the response of capital flows to price shocks}

We begin by using a standard mean-variance model of portfolio choice, as considered, for example, in Bohn and Tesar (1996), to explain time variation in portfolio rebalancing. A representative 
investor chooses a portfolio of risky assets to maximize

$$
\max _{\mathbf{x}_{t}} E_{t}\left(R_{t+1}^{p}\right)-\frac{1}{2} \alpha \operatorname{Var}_{t}\left(R_{t+1}^{p}\right)
$$

where $\mathbf{x}_{t}$ is the vector of portfolio shares of risky assets and $\alpha$ is the coefficient of relative risk aversion. The portfolio return $R_{t+1}^{p}$ is

$$
R_{t+1}^{p}=\mathbf{x}_{t}^{\prime} \mathbf{R}_{t+1}+R_{t+1}^{f}
$$

where $R_{t+1}^{f}$ is the return on a risk-free asset and $\mathbf{R}_{t+1}$ is a vector whose $k$ th entry is the excess return on risky asset $k, R_{k t}$. The mean and variance of the portfolio return (conditional on the investor's information set) are

$$
\begin{aligned}
E_{t}\left(R_{t+1}^{p}\right) & =\mathbf{x}_{t}^{\prime} \bar{\mu}_{t}+R_{t+1}^{f}, \\
\operatorname{Var}_{t}\left(R_{t+1}^{p}\right) & =\mathbf{x}_{t}^{\prime} \boldsymbol{\Sigma}_{t} \mathbf{x}_{t},
\end{aligned}
$$

where $\bar{\mu}_{t} \equiv E_{t}\left(\mathbf{R}_{t+1}\right)$ and $\boldsymbol{\Sigma}_{t} \equiv \operatorname{Var}_{t}\left(\mathbf{R}_{t+1}\right)$. The first-order condition of the maximization problem gives

$$
\mathbf{x}_{t}=\frac{1}{\alpha} \boldsymbol{\Sigma}_{t}^{-1} \bar{\mu}_{t} .
$$

The share of wealth invested in asset $k, x_{k t}$ is then given by

$$
x_{k t}=\frac{1}{\alpha} \mathbf{e}_{k}^{\prime} \boldsymbol{\Sigma}_{t}^{-1} \bar{\mu}_{t}
$$

where $\mathbf{e}_{k}$ is a vector containing 1 in the $k$ th position and zeros otherwise.

The investor's wealth evolves according to

$$
W_{t}=\left(1+R_{t}^{p}\right) W_{t-1} .
$$

If the investor chose to hold a share of $x_{k t-1}$ of his wealth in security $k$ at the beginning of period $t-1$, his holdings of that security before re-adjusting his portfolio in $t$ are $\left(1+R_{k t}\right) x_{k t-1} W_{t-1}$. Therefore, by definition, the investor's net purchases of security $k, N P_{k t}$ are equal to

$$
\begin{aligned}
N P_{k t} & =x_{k t} W_{t}-\left(1+R_{k t}\right) x_{k t-1} W_{t-1} \\
& \approx \underbrace{\left(R_{t}^{p}-R_{k t}\right) x_{k t-1} W_{t-1}}_{\text {portfolio rebalancing }}+\underbrace{\left(x_{k t}-x_{k t-1}\right) W_{t-1}}_{\text {change in portfolio shares }} .
\end{aligned}
$$

In the second line, we have approximated $x_{k t} \approx x_{k t-1}$ in the first term on the right-hand side, following Bohn and Tesar (1996). The first term in (2) represents portfolio rebalancing: if the return of security $k$ falls below the return of the market portfolio, the investor purchases that 
security to maintain constant portfolio shares. The second term represents asset purchases due to changes in the investor's desired portfolio shares.

Now, consider a situation of financial stress or heightened uncertainty captured in the model by some combination of higher risk aversion (increase in $\alpha$ ), lower expected return on security $k$ (fall in $\bar{\mu}_{k t}$ ), and higher variance of asset $k$ 's return (increase in $\sigma_{k t}$, the $k, k$ entry in $\boldsymbol{\Sigma}_{t}$ ). From (1), any of these changes will lower the optimal portfolio share of security $k .{ }^{5}$ Consequently, a regime switch from an environment of low to an environment of high financial stress is associated with net sales of security $k$ or, in an international context, with a capital flow out of region $k$. In the empirical results below, we will interpret the impulse responses of capital flows between the United States and emerging markets to a regime switch as reflecting changes in investors' desired portfolio shares.

Once the portfolio share has been adjusted and barring further changes in the desired portfolio share, the response of net purchases $N P_{k t}$ to returns that is due to portfolio rebalancing decreases. To see this, note that from (2), we have

$$
\left.\frac{\partial N P_{k t}}{\partial R_{k t}}\right|_{x_{k t}=x_{k t-1}}=-x_{k t} W_{t-1}
$$

so that the magnitude of the flow is decreasing in investors' position in security $k$. This is intuitive. With a lower portfolio share, a given shock has a smaller effect on the amount of wealth invested in security $k$, and hence, lower asset sales or purchases are required to rebalance the portfolio. The onset of a period of financial stress initially leads to capital flows out of risky assets, and while financial stress remains elevated, the stabilizing effect of portfolio rebalancing is dampened.

\subsection{Time variation in the price effects of capital flows}

Next, consider the effect of a capital flow shock to exchange rates and equity prices. In many models, no capital flows are required to move prices, which instantly adjust to their new equilibrium level in response to news. In practice, empirical work has documented that capital flows do have an effect on exchange rates (see, for example, Hau et al. 2010).

One model that allows us to think about this effect is that of Gabaix and Maggiori (2015). In this model, representative households in two countries can buy and sell foreign bonds only through financial intermediaries. These intermediaries face balance sheet constraints that limit their risk taking. The key parameter in the model, $\Gamma$, captures the risk-bearing capacity of financial intermediaries. A higher value of $\Gamma$ means that intermediaries are less able or willing to take on balance sheet risks. Therefore, when $\Gamma$ increases, intermediaries have to be compensated for taking on risk through a higher expected return, and hence, capital flows are associated with a greater

\footnotetext{
${ }^{5}$ For example, Caporale et al. (2015) provide empirical evidence that exchange rate uncertainty typically has a negative effect on net capital flows (based on TIC data), suggesting that risk-averse investors scale back their investments in foreign-currency assets to minimize FX risk exposure.
} 
effect on prices. ${ }^{6}$ Periods of financial stress can be thought of as periods when intermediaries' risk bearing capacity is low. It follows that a given capital flow should have a greater effect on exchange rates (and on equity prices, if equity can also be traded only via financial intermediaries) in periods of high financial stress.

A further reason why the effect of capital flows on returns is expected to be higher in times of financial stress is that risky assets are likely to become less liquid in such periods.

\section{Empirical framework}

This section discusses the empirical strategy in two subsections. The first subsection presents the time-varying framework and the motivation for using a Markov-switching VAR approach. The second subsection discusses the identification strategy to understand the dynamics of portfolio rebalancing.

\subsection{Estimating changes in parameters}

To analyze whether the time-varying relationship between equity flows, equity returns, and exchange rate returns in periods of high and low financial stress, we estimate a Markov-switching VAR (MSVAR). In this empirical setup, both the coefficients and the variances are allowed to switch between regimes. The objective is to identify specific periods in which the variables respond to different shocks. The MSVAR approach is preferred over models that allow for gradual changes in coefficients and variances over time (as in the TVP-VARs proposed by Primicieri (2005) or Cogley and Sargent (2005)) because periods of high financial stress are assumed to be a priori not highly persistent. Therefore, short-lived effects related to crisis periods may not be detected with more complex models in which all parameters are allowed to change in each period.

Formally, the structural MSVAR with $p$ lags can be written as:

$$
A_{0, s} y_{t}=c_{s}+\sum_{k=1}^{p} A_{k, s} y_{t-k}+\epsilon_{t}
$$

where $y_{t}$ is a $3 \times 1$ vector containing the equity excess return, the exchange rate return, and the standardized net equity flows at time $t$ and $A_{k, s}$ are $3 \times 3$ coefficient matrices. The structural shock vector (which is normalized to follow the standard normal distribution), $\epsilon_{t}$, is $3 \times 1$, and the constant for each equation, $c_{s}$, is $3 \times 1$. The subscript $s \in\{1,2\}$ indicates two regimes. The regime evolves according to a hidden Markov-switching process with an unrestricted transition matrix $Q$. Because sign restrictions are used as the identification scheme, we need to draw from the posterior

\footnotetext{
${ }^{6}$ See, for example, proposition 4 in Gabaix in Maggiori (2015), which shows that in their model, the effect of a capital flow shock $f^{*}$ on the exchange rate is increasing in $\Gamma$.
} 
distribution of the coefficients; thus, we use Bayesian methods to estimate the reduced form model:

$$
y_{t}=B_{s} X_{t}+A_{0, s}^{-1} \epsilon_{t}
$$

where $B_{s}$ is a $3 \times(3 p+1)$ matrix containing the reduced form coefficients for each equation ordered by their lags. $X_{t}$ is a $(3 p+1) \times 1$ vector with the lagged variables and a $3 \times 1$ vector of ones stacked on top of each other.

To draw from the posterior distribution, two sets of priors need to be defined. ${ }^{7}$ For the VAR parameters, we use priors as proposed by Sims and Zha (1998). By setting the hyperparameter $\lambda_{0}=$ 1 and by using an inverse Wishart prior for the reduced form covariance matrix $\Sigma_{s}=\left(A_{0, s}^{-1}\right)\left(A_{0, s}^{-1}\right)^{\prime}$, we assume prior independence across structural equations and thus do not impose any prior on $A_{0} .{ }^{8}$ Because the variables are assumed to be stationary, we set the priors on drifts or forecasts to zero $\left(\mu_{5}=\mu_{6}=0\right)$ and choose the hyperparameter $\lambda_{4}=0.1$. This reflects the belief that the constants should be close to zero. Following Sims and Zha (1998), we set the hyperparameter for the lag decay to $\lambda_{3}=1$. Finally, we set the hyperparameter $\lambda_{1}=0.5$, which is the hyperparameter governing the tightness of the prior on the $\operatorname{AR}(1)$ coefficients. For the Markov transition matrix $Q$, we follow the Markov-switching literature and use an unrestricted prior of the Dirichlet form (e.g., Sims, Waggoner and Zha (2008)). The Dirichlet prior is set such that one of the states is not persistent, reflecting a belief that periods of high financial stress are short lived. ${ }^{9}$

When sampling from the unconstrained posterior, which sampled parameter corresponds to which state is unknown because label switching might have occurred (see, for example, FrühwirthSchnatter, 2006). To account for this non-identifiability, we follow Frühwirth-Schnatter (2001) and first use a random permutation sampler to draw parameters from the posterior distribution. Analysis of the unconstrained marginal posterior densities reveals that the two states are best identified using the $\mathrm{AR}(1)$ parameter of exchange rate returns in both samples. This identifiability constraint is then imposed by permuting each parameter draw so that the constraint is satisfied. Using the constraint, we generate one million draws from the posterior distribution with a Metroplis Hastings algorithm. For the presentation of the results, only the last 500'000 of these draws are used. To initialize the sampler, the mode of the posterior was calculated following the suggestions of Sims, Waggoner and Zha (2008). The parameters are split into the following four blocks: the intercepts $c_{s}$, the AR coefficients $B_{s}$, the error covariances $\Sigma_{s}$, and the transition matrix $Q$. Within each block, the maximum for the posterior log likelihood is found, with the parameters in the other blocks held constant.

\footnotetext{
${ }^{7}$ These calculations have been performed using the R-package "MSBVAR", which is maintained by Patrick Brandt.

${ }^{8}$ See example 5.1 in Sims and Zha (1998).

${ }^{9}$ In the notation of Sims, Waggoner and Zha (2008), we use $\alpha_{11}=5$ and $\alpha_{22}=\alpha_{12}=\alpha_{21}=2$.
} 
Table 1: Identification restrictions

\begin{tabular}{lccc} 
& EQ return shock. & FX return shock & EQ flow shock \\
\hline EQ return & + & + & + \\
FX return & + & + & - \\
EQ flow & - & + & + \\
\hline
\end{tabular}

Notes: This table summarizes the identification restrictions on the contemporaneous (within the same month) effect of shocks to the variables in columns on the variables in rows. The signs are listed for positive shocks. A positive equity return differential ("EQ return") is a higher return abroad than in the United States; a positive FX return represents a dollar appreciation; a positive equity flow is a net flow out of the United States. Columns 1, 2 and 3 correspond to hypotheses H1, H2 and H3 in Hau and Rey (2004).

\subsection{Identification and generalized impulse responses}

The structural matrix $A_{0, k}$ is identified using sign restrictions on the contemporaneous effect of shocks. These restrictions are shown in Table 1. The restrictions follow Hau and Rey (2004) and are based on the portfolio rebalancing theory and thus particularly on the assumption that investors do not fully hedge their FX portfolio risk. The sign restrictions rest on three hypotheses, which correspond to the three columns in Table 1. First, because of incomplete hedging, a positive equity return differential shock leaves investors heavily exposed to foreign currency. Portfolio rebalancing then implies that investors sell their foreign equity and invest in U.S. stocks, thus generating equity flows to the United States and U.S. dollar (USD) appreciation. Second, USD appreciation leaves investors with too much exposure to U.S. currency (again, we assume incomplete hedging). Investors then rebalance their portfolio by selling U.S. equity and moving capital to the foreign market, thereby generating an equity outflow from the United States and lowering U.S. equity returns. Third, a positive equity flow shock, corresponding to an equity outflow from the United States, directly affects exchange rates and equity markets. As capital is moving into foreign equity markets, the demand for foreign currency and foreign equity increases, which results in USD depreciation and increasing foreign equity returns.

Assuming the system is in state $s$, the $k$-period ahead generalized impulse responses of variable $i$ to a shock to variable $j$ are computed as the difference in the conditional expectations with and without a structural shock:

$$
I R F_{i j, t+k}=\mathbb{E}\left(y_{i, t+k} \mid \epsilon_{j, t} X_{t}, s_{t}=s\right)-\mathbb{E}\left(y_{i, t+k} \mid X_{t}, s_{t}=s\right)
$$

where $\epsilon_{j, t}$ is the structural shock vector, with the $j$ th row being the only non-zero element and equal to one. By using generalized impulse responses, we account for the fact that high stress periods are likely to be short lived. When a state lasts only for one or two months at a time, using impulse 
responses conditional on staying in a given regime, as Ehrmann et al. (2003) suggest, would be misleading. This is because the probability of staying in the short-lived regime is extremely small (Krolzig, 2006). Further details on the computation of generalized impulse responses are provided in Appendix A.

The identification through sign restrictions is performed using the procedure proposed by RubioRamírez et al. (2010), as implemented by Baumeister and Peersman (2013). Let $R$ be a diagonal matrix whose elements are normalized to be positive and $Q$ be a rotation matrix from the $Q R$ decomposition of a $3 \times 3$ matrix drawn from the standard normal distribution. Further, let $\Sigma_{k \in\{S, T\}}=P_{k} D_{k} P_{k}^{\prime}$ be the eigenvalue-eigenvector decomposition of the covariance matrix $\Sigma_{k \in\{S, T\}}$ drawn from the marginal posterior distribution of regime or period $k$. Then, the matrix of the contemporaneous effect for regime or period $k$ can be calculated as follows:

$$
A_{0, k}^{-1}=P_{k} D_{k}^{\frac{1}{2}} Q_{k}^{\prime}
$$

Because the matrix of the contemporaneous effect corresponds to the impulse response on the contemporaneous effect of the shock, the elements need to be in line with our sign restrictions. Given a draw for the covariance matrix, we generate rotations $Q$ until we have found 200 that lead to the matrix of the contemporaneous effect satisfying our sign restrictions. Then, the mean is calculated across the rotations. This procedure is performed for 1000 draws of the covariance matrix for each regime of period $k \in\{S, T\}$. This generates the posterior distribution of impulse responses shown in our results.

To characterize the states, we also present how the variables respond to a regime switch. Similar to the generalized impulse responses, we define the response of variable $i$ to a switch from regime $s$ to regime $h$ in period $t$ as:

$$
I R F_{i, s h, t+k}=\mathbb{E}\left(y_{i, t+k} \mid s_{t}=h, X_{t}\right)-\mathbb{E}\left(y_{i, t+k} \mid s_{t}=s, X_{t}\right)
$$

In a model with two states, this definition implies that the response to switching from regime $s$ to regime $h$ is the negative value of a switch in the other direction. The response to regime switches depends not on the structural identification and only on the reduced-form coefficients. Consequently, it can be calculated directly by drawing from the posterior distribution of the reduced-form coefficients. As shown in Appendix B, the response to a regime switch depends on the variables' values in $t$. We therefore calculate the response at every observation in the sample and take the mean over the calculated responses separately for each draw. This procedure is repeated for 10'000 draws, which generates the posterior distribution of responses shown in our results. 


\section{Data}

We use monthly country-level data for equity returns, foreign exchange rate returns, and equity flows for the period from January 1995 to December 2015. We aggregate the data for two sets of countries: 19 advanced and 14 emerging market economies. Portfolio rebalancing in our setup constitutes portfolio adjustment between the United States and groups of investment assets in advanced and emerging market economies. Our choice of countries is based on the size of equity flows with a minimum $1 \%$ threshold for each country group. A complete list of the countries included in the two samples is provided in Table 3 in Appendix C.

As in Hau and Rex (2004), the data on international equity flows are from the U.S. Department of the Treasury (TIC data). These data measure bilateral flows between the United States and various countries. ${ }^{10}$ Net equity flows are defined as net purchases of foreign stocks by U.S. residents minus net purchases of U.S. stocks by foreign residents. ${ }^{11}$ Positive net equity flows thus correspond to outflows from the U.S. perspective. Equity flows have strongly increased during the sample period. We therefore follow Hau and Rey (2004) and standardize monthly net equity flows with the total monthly flows after aggregating the flows within the two samples for advanced and emerging market economies. The transformed equity flows are multiplied by 100 and are thus bounded between -100 and 100 .

Equity and exchange rate data are from Datastream. ${ }^{12}$ The equity return differential is calculated as the difference between the MSCI index local currency returns of the foreign country and the United States, where returns are calculated using log differences of the end-of-month index values. ${ }^{13}$ Positive monthly excess equity returns imply that foreign equities outperform U.S. equities. A positive exchange rate return corresponds to a USD appreciation and is calculated as the log difference of the end-of-month nominal exchange rates expressed in USD.

To aggregate equity and exchange rate returns within the two country samples, we weight them by the countries' contributions to total flows in the specific month. Formally, the weight for each country $i$ in month $t$ for sample $S$ is:

$$
w_{i, t}=\frac{T F_{i, t}}{\sum_{i \in S} T F_{i, t}}
$$

where $T F_{i, t}$ represents the total equity flows between country $i$ and the United States in period $t$. Aggregating the data has several advantages. First, the custodian and transaction biases in the TIC data mentioned by various authors (e.g., Griever et al. (2001)) are irrelevant for advanced economies

\footnotetext{
${ }^{10}$ Griever et al. (2001) provide an extensive overview on the TIC data. The data can be downloaded on the website of the U.S. Department of the Treasury.

${ }^{11}$ Following Hau and Rey (2004) and subsequent papers, we focus only on equity flows. Empirical work has mostly found that capital flows related to equity purchases, rather than bond purchases, are an important determinant of exchange rates (see, for example, Gyntelberg et al. (2015)).

${ }^{12}$ The respective tickers are provided in Table 3 in Appendix C.

${ }^{13}$ End of month is defined as the last day of a month for which data are available.
} 
Table 2: Summary Statistics

\begin{tabular}{lcccccccc} 
& Mean & Min. & Max. & Var. & Kurt. & Skew. & $\mathrm{AC}(1)$ & $\mathrm{AC}(2)$ \\
\hline Advanced Economies & & & & & & & & \\
EQ return & -0.31 & -12.58 & 5.71 & 4.92 & 6.04 & -0.54 & -0.15 & -0.05 \\
FX return & 0.03 & -7.37 & 9.57 & 4.68 & 4.65 & 0.33 & 0.02 & 0.05 \\
EQ flow & -0.19 & -4.87 & 9.25 & 4.67 & 4.23 & 0.47 & 0.56 & 0.51 \\
\hline Em. Market Economies & & & & & & & & \\
EQ return & -0.02 & -21.56 & 9.81 & 16.38 & 7.65 & -1.18 & 0.14 & 0.09 \\
FX return & 0.37 & -5.81 & 17.81 & 5.78 & 14.88 & 2.01 & 0.07 & 0.01 \\
EQ flow & 3.87 & -15.01 & 37.41 & 47.12 & 5.47 & 1.07 & 0.43 & 0.30 \\
\hline
\end{tabular}

Notes: This table shows the summary statistics for the weighted variables in the two samples. $\mathrm{AC}(1)$ refers to the autocorrelation of the first, $\mathrm{AC}(2)$ of the second lag.

as a whole and are likely to be less severe for emerging market economies. Second, international equity flows from the United States to these country groups are more important for the groups' overall equity market, as compared with the flows to just a single country (which will also have flows to and from many countries besides the United States). Equity flows within the group do not matter because they affect both countries, therefore cancelling the overall equity effect for the group.

Table 2 presents summary statistics of the three variables for advanced and emerging market economies. Three observations standout. First, most variables are centered around zero, except for the positive mean for net equity flows to emerging market economies. A positive mean indicates, on average, equity flows out of the United States and into emerging market economies. Second, the four moments of the variables for emerging market economies are larger than the corresponding moments for advanced economies. The variance of net equity flows for emerging market economies is particularly pronounced, as is the kurtosis of exchange rate returns. Third, despite these differences in the moments, the level of persistence of the variables (captured by the autocorrelation coefficients) tends to be similar for advanced and emerging market economies.

Data for two commonly used indicators of financial stress are the CBOE Volatility Index (VIX) and the Emerging Bond Index Global Sovereign Spread (EMBI). The VIX is from the Chicago Board Options Exchange, and it measures market expectations of volatility, which are derived from the S\&P 500 stock index option prices. ${ }^{14}$ The EMBI is compiled by J.P. Morgan and tracks returns of sovereign bonds from various emerging market economies. ${ }^{15}$ Presented is the spread of the sovereign bonds against benchmark U.S. Treasury bonds.

Figure 1 plots the three variables for both advanced and emerging market economies. The plots highlight three features of the data. First, the variables appear to follow stationary processes.

\footnotetext{
${ }^{14}$ VIX data were downloaded from Datstream with the ticker CBOEVIX.

${ }^{15}$ EMBI data were downloaded from Bloomberg with the ticker JPEGSOSD.
} 
Figure 1: Data series
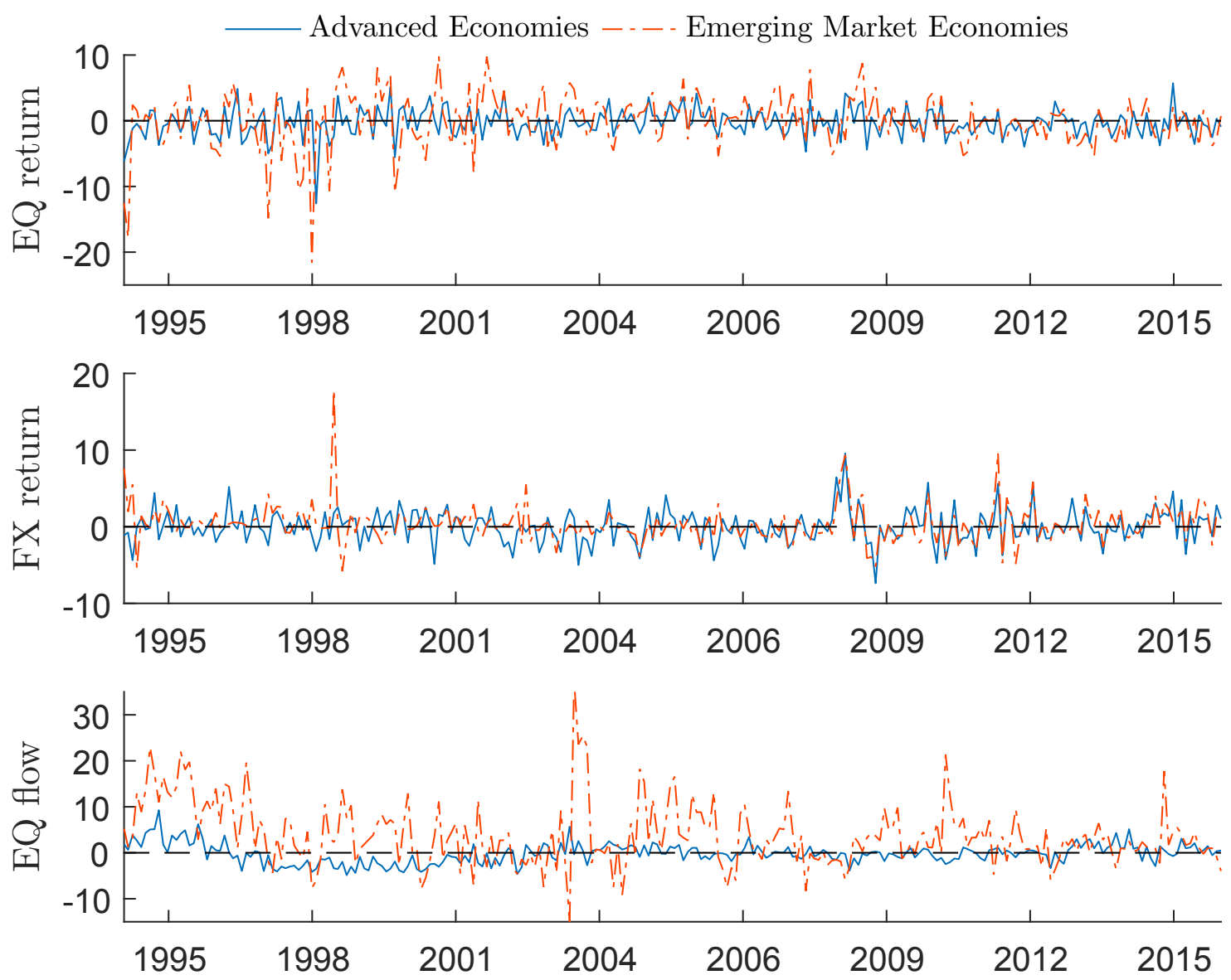

Second, the depreciation of the USD against emerging market currencies during the Asian crisis, the global financial crisis, and the euro area sovereign debt crisis is visible. Third, as in Table 2, the elevated variance in equity outflows to emerging market economies is visible in Figure 1.

\section{Results}

The empirical results from the MSVAR model are presented in two subsections. The first subsection shows that the two states, which are identified endogenously by the model, can be interpreted as capturing periods of low and high financial stress. In particular, it is argued that switches to and from the second state match the sharp movements in popular risk measures, such as the VIX index. The second subsection reports the baseline findings that the dynamics of equity returns, exchange rate returns, and equity flows, which are consistent with portfolio rebalancing, are time varying for emerging market economies, whereas the dynamics are found to be stable for advanced economies. The discussion highlights the differences in the dynamics of equity flows, equity returns, 
Figure 2: State probabilities

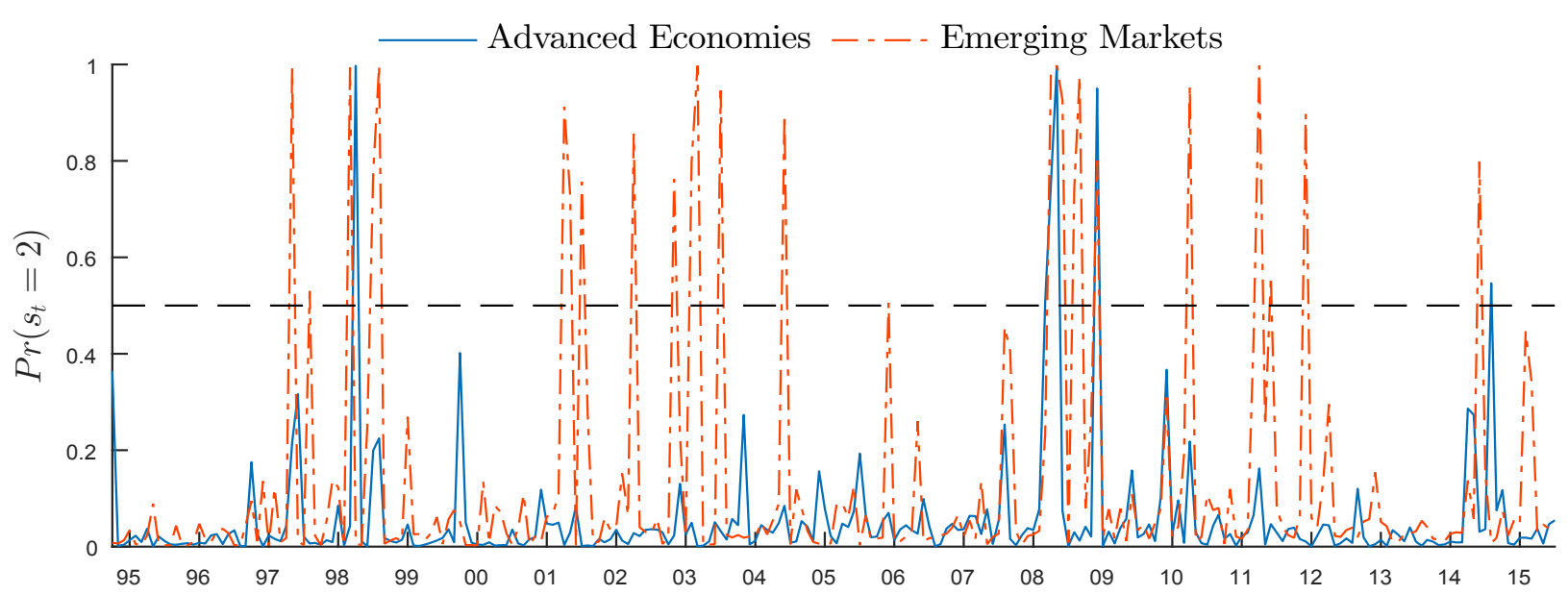

Notes: Posterior probability of being in state two, calculated for each period as the mean over the posterior sample of the two states.

and exchange rate returns using generalized impulse responses for periods of high and low financial stress.

\subsection{Identified regimes as periods of low and high financial stress}

Figure 2 shows how the posterior probability of being in the second state changes over time. For the advanced economies (AE) sample, the second state exhibits little persistence and occurs infrequently. Throughout most of the AE sample, the system remains in the first state. For the emerging market economies (EME) sample, the second state also shows little persistence, but it arises more frequently than in the AE sample. There is some overlap between the estimates for the two states in the $\mathrm{AE}$ and EME samples: If advanced economies enter in the second state, emerging market economies also do, and many of the peaks in the EME sample coincide with peaks in the probability of the AE model. ${ }^{16}$

The observed pattern in Figure 2 for the AE and EME sample is in line with what would be expected of a system with periods of high and low financial stress. Periods of low financial stress prevail throughout most of the sample and are interrupted by a few episodes of non-persistent, high stress. However, the two states by themselves do not have any economic meaning, because they are endogenously determined in the Markov-switching model and only indicate that the variables behave differently in some periods. To offer an interpretation for the posterior state probabilities, the behaviors of the states are compared with movements in the VIX index (a measure of U.S. stock market volatility) and the EMBI index (a measure of the spread between bond yields in emerging

\footnotetext{
${ }^{16}$ An exception is September 1998. The EME estimates enter the second state one month earlier than the AE estimates.
} 
market economies and the United States). These indices are commonly used measures for financial market stress in advanced and emerging market economies, with peaks signaling periods of high financial stress.

Figure 3 plots the VIX index and the EMBI index against period 2 episodes as estimated from the Markov-switching model. The light shaded areas indicate periods when the probability of being in the second state is larger than 0.5 in the EME sample. The dark shaded areas correspond to the same probability for the second state for the AE sample. The comparison shows that the states are well aligned with periods when financial stress indicators are high. For both the AE and EME sample, the model detects stress periods for the two major financial crises: (i) the Russian financial crisis starting in August 1998 and (ii) the global financial crisis starting in September 2008 with the Lehman Brothers' bankruptcy. An additional stress period is detected in both samples for May 2009. This is not a peak in the stress indicators; rather, it is a month marked by an exceptional USD depreciation, as indicated by the negative peak in Figure 1. In the EME sample, the model detects further periods of high financial stress. For example, the periods in mid-2001 and mid-2011, which are identified to be in the second state, are well aligned with peaks in the financial stress indicators and correspond to the 9/11 attacks in the United States and the European sovereign debt crisis.

For the year 2003, the model identifies multiple periods when the EME sample is in the second state. These periods are not aligned with the stress indicators and are more difficult to interpret. However, in 2003, we observe strong swings in equity flows, largely driven by flows to and from a single country, Taiwan, that was heavily affected by severe acute respiratory syndrome (SARS) between November 2002 and July 2003. The high volatility in equity flows in itself can also be an indicator of uncertainty, as U.S. investors move capital towards and again away from Taiwan from one month to the next. The model also identifies some additional periods when either the EME or the AE sample is in the second state. Again, these periods are well aligned with small peaks in the risk measures and indicate periods of financial stress.

We interpret the evidence from Figures 2 and 3 such that the second state corresponds to periods of high financial stress. It is important to note that the non-persistent pattern in the posterior state probability of state two does not arise from our selected priors. In general, the Dirichlet prior governs how the states are drawn, and the choice of the Dirichlet prior can push the results towards more or less persistence in the states. However, the second state is less persistent than the applied prior implies, indicating that the posterior state probabilities are governed by the data and are not determined by the choice of priors. Furthermore, adjusting the Dirichlet prior so that the states are a priori symmetric and persistent does not change the results.

The two states are further characterized by how the variables respond to a regime change. Figure 4 reports how the three variables respond over time following a switch from state 1 to state $2 .{ }^{17}$

\footnotetext{
${ }^{17}$ By definition, switching from the high stress to the low stress state generates opposite responses of the same magnitude.
} 
Figure 3: Indicators of financial stress and state 2 episodes

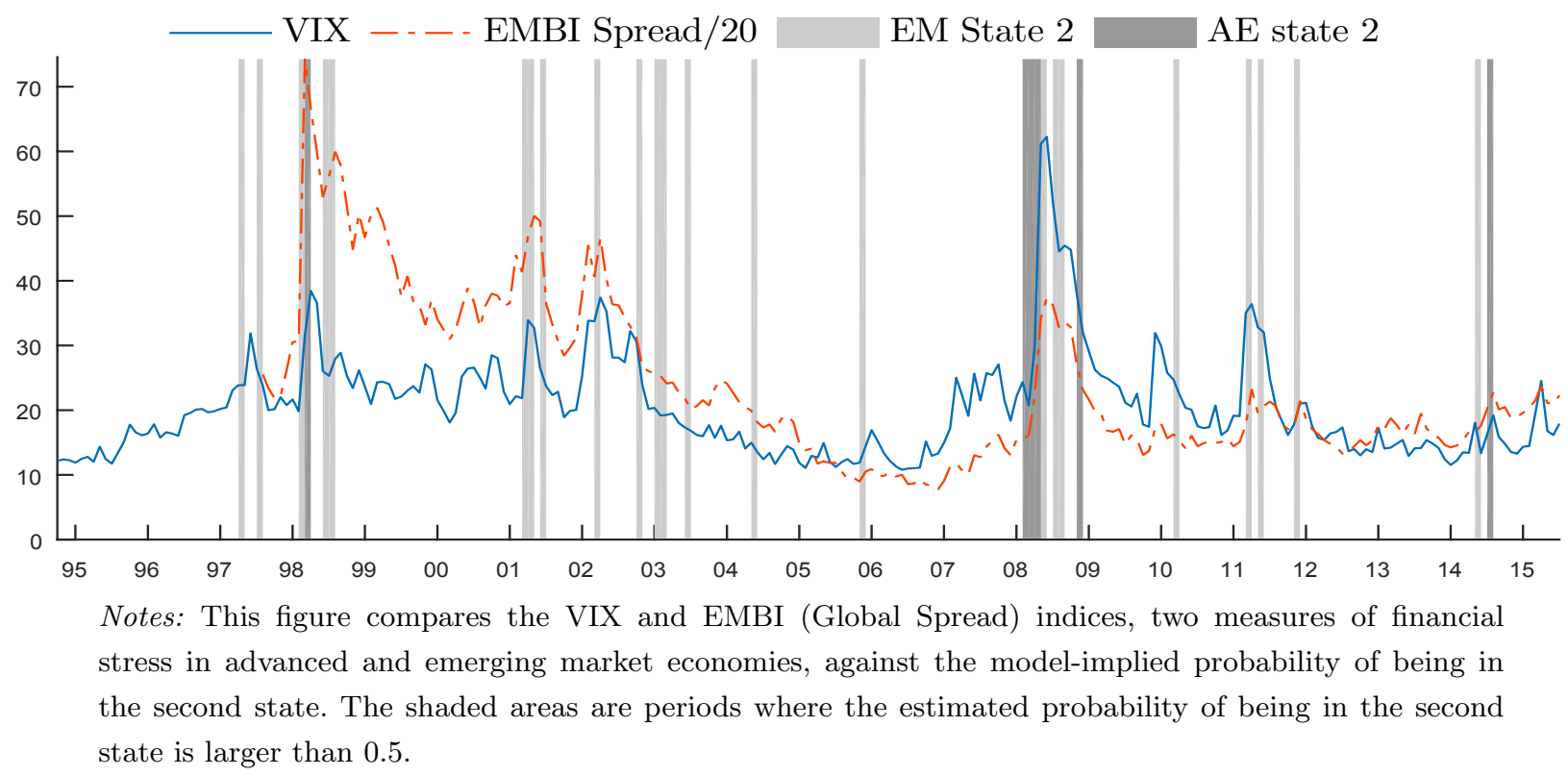

In the $\mathrm{AE}$ sample, the response is close to zero, indicating that there may not be much difference between the two states. In the EME sample, there is a clear response when switching from state 1 to state 2. Expected emerging market excess equity returns over returns in the United States drop, whereas expected exchange rate returns increase by approximately $0.5 \%$ (a USD appreciation). Furthermore, equity flows react negatively (a capital flow out of emerging market economies), and the $68 \%$ credible set of all these responses is non-zero. After a few periods, the responses are close to zero, as the state probabilities converge towards their long-run mean.

This last result provides further evidence that state 2 corresponds to high stress periods in the EME sample. The estimated responses show that switching to state 2 in a month implies that for this month, foreign equities underperform U.S. equities, that the USD appreciates, and that capital moves away from EMEs to the United States. This is consistent with what we would expect during high stress periods. In high stress periods, U.S. investors tend to move out of risky emerging market equities and repatriate capital back home. This lowers equity prices in EMEs and puts pressure on their exchange rates.

\subsection{Impulse responses for periods of low and high financial stress}

The signs of the impulse responses to the three shocks satisfy by construction the restrictions defined in Table 1. After the contemporaneous effect to the shock, impulse responses with a 12month horizon can move in either direction. If the channels of portfolio rebalancing do not hold in periods of low or high financial stress, no impulse responses fitting the sign restrictions would be found. The full results for both samples presented in Appendix C, however, show that this is 
Figure 4: Responses to a switch from state 1 to state 2
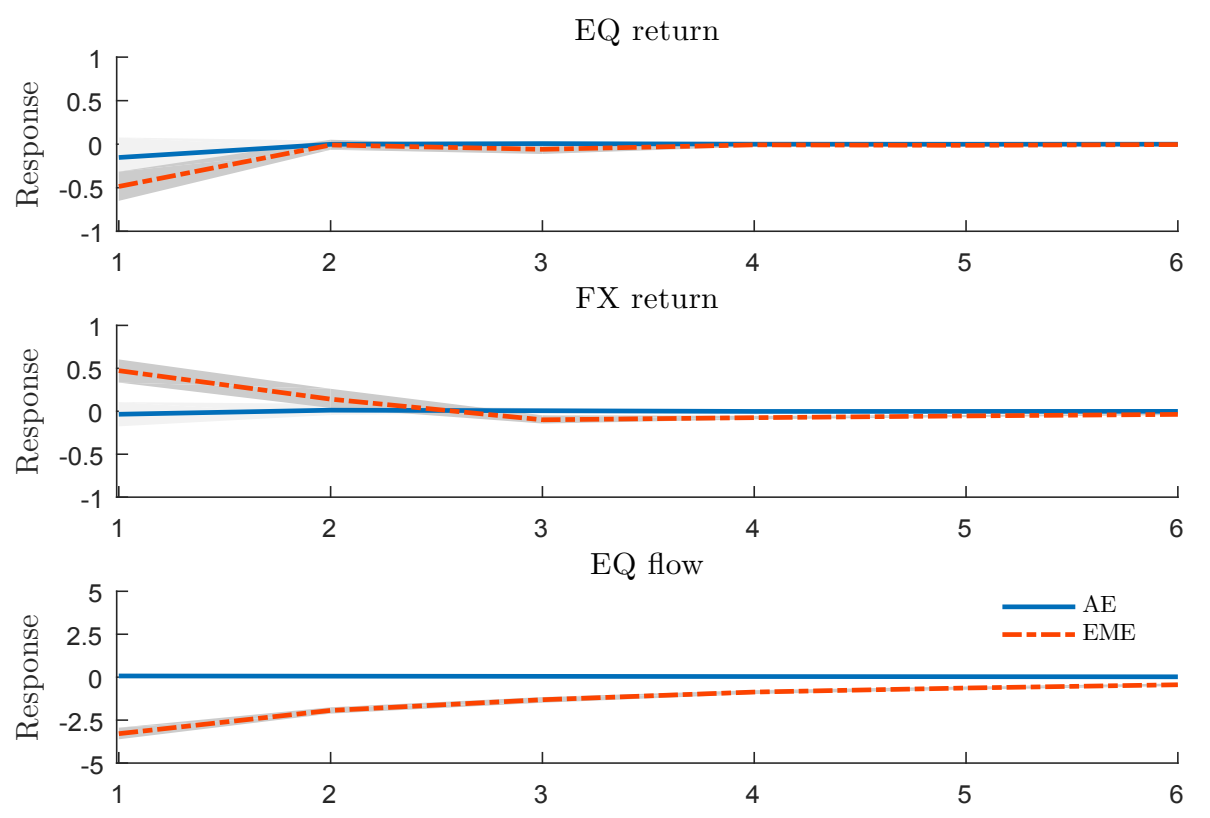

Notes: This figure shows how the three variables are expected to respond over time following a switch from state 1 (i.e., low financial stress) to state 2 (i.e., high financial stress). The lines correspond to the median, and the shaded areas correspond to the $68 \%$ posterior credible set.

not the case and that the sign restrictions fit well. The restrictions hold beyond the period of the shock's contemporaneous effect. In sign and magnitude, the impulse responses are in line with the results of Hau and Rey (2004). ${ }^{18}$ Further, the adjustment over time shows a pattern similar to that in Hau and Rey (2004). Equity excess returns and exchange rate returns react within one to two months, whereas net flows continue to adjust during the year. Overall, the fact that we can find impulse responses that satisfy the sign restrictions implied by the theory suggests that portfolio rebalancing offers a good description of investor behavior for U.S. equity flows towards advanced and emerging economies.

One notable difference in the Markov-switching results from those of Hau and Rey (2004) is that price responses to flow shocks in the Markov-switching model are larger in absolute terms. This can partially be attributed to the choice of the aggregated samples. Hau and Rey (2004) analyze flows between the United States and individual advanced economies. In their setting, flows to and from other countries besides the United States are ignored. Consequently, price responses are lower

\footnotetext{
${ }^{18}$ Note that we are presenting the impulse responses to shocks normalized so that they correspond to a shock of one percentage point (e.g., equity excess returns increase from $4 \%$ to $5 \%$ ). This makes it possible to compare impulse responses across the two states (recall that the shock standard deviations also change across states). To make the results comparable, Hau and Rey's (2004) impulse responses need to be adjusted so that the effect of a shock by itself is equal to one.
} 
Figure 5: GIRFs of equity flows to equity and exchange rate shocks
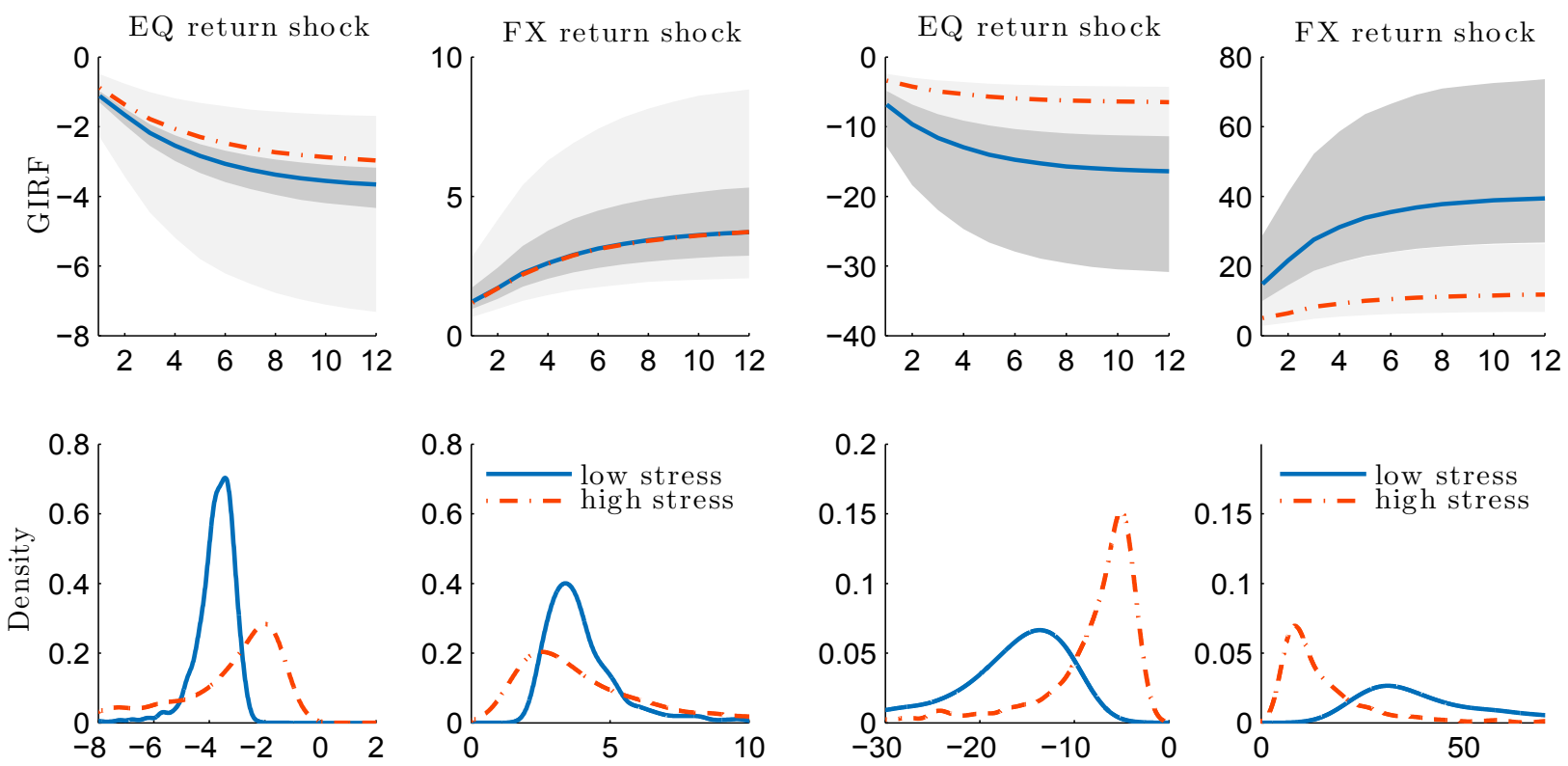

(a) Advanced Economies

(b) Emerging Market Economies

Notes: Cumulative generalized impulse responses (GIRF) of net equity flows in the two samples. The upper row shows how net flows react to the two price shocks over time. The shocks are normalized so that they correspond to a shock of one percentage point in the respective returns. The lines correspond to the median, and the shaded areas correspond to the $68 \%$ posterior credible set. The lower row shows the posterior density of the same impulse responses after 12 months. State 1 denotes periods of low financial stress and state 2 periods of high financial stress.

if flows from countries besides the United States move in the opposite direction. For example, in a given month, if U.S. investors buy Japanese equities but European investors simultaneously sell Japanese equities, then the price effect of U.S. flows is attenuated. With the aggregated samples, this is not the case because the price effects of flows within a country group cancel each other out in the aggregate, and we observe only the price response to U.S. flows.

Next, the discussion of the main findings from the Markov-switching model focuses on a subset of impulse responses and compares them across the two regime states. Panel (a) in Figure 5 shows how U.S. equity flows in the AE sample respond to a $1 \%$ shock to equity or foreign exchange rate returns. The first row shows the median and $68 \%$ credible bands, whereas the second row shows the complete distribution of the impulse response after 12 months across models that satisfy all sign restrictions. Note that the distribution of the net flow response to an equity return shock differs between states and that the median response in periods of stress (in the second state) is closer to zero. Because of the large overlap of the two distributions, however, no clear conclusion regarding whether portfolio rebalancing between the United States and other advanced economies changes in periods of high and low financial stress can be drawn. The time-varying evidence for advanced 
economies suggests that the dynamics for net equity flows, exchange rate returns, and equity returns are consistent with portfolio rebalancing in both high and low financial stress periods.

Panel (b) reports the same impulse responses for the EME sample. As in the AE sample, equity flows to and from emerging market economies are less sensitive to exchange rate and equity shocks in periods of high financial stress. There are, however, distinguishable differences between states in the posterior distribution of the impulse responses, and the median of the high stress state exceeds the $68 \%$ credible set of the low stress state. This statistical difference in the equity flow responses provides strong evidence that in periods of high financial stress, the dynamics consistent with portfolio rebalancing generate smaller equity flows. This empirical result accords with the theoretical discussion in section 2. In periods of high financial stress, investors seek to reduce their equity exposure and hold a large share of their portfolio in less risky investments. The dynamics of portfolio rebalancing generate smaller equity flows in response to equity and exchange rate shocks. The level of portfolio adjustments in terms of rebalancing across asset classes cannot be measured with our specification. However, because the data for equity flows are based on purchases and sales of equities, equity flow shocks indicate shifts to and from equities.

Note that the scales in Figure 5 differ for the AE and EME results. If these results were plotted on the same scale, one would hardly see the difference in impulse responses for states 1 and 2 in the AE case. It would then become even more clear that the dynamics are quite stable across the two regimes for the AE sample but time varying for the EME sample.

Portfolio rebalancing tends to dampen the effect of adverse shocks; thus, it could act as a stabilizing force even during crisis periods. Consider an emerging market crisis, which could be captured by adverse equity or currency return shocks in our empirical setting. Such adverse shocks would leave international investors holding too little (measured in USD) emerging market equity in their portfolios. This would prompt capital flows to emerging market economies, which would mitigate the initial shocks. Because the response of equity flows is observed to be much smaller in absolute value in the second state - which closely corresponds to periods of financial turmoil in emerging market economies - the stabilizing force of portfolio rebalancing is weaker in periods of high financial stress.

When comparing the magnitude of the impulse responses between advanced and emerging market economies, it is important to note that the standard deviations of price and flow shocks are much higher for the EME sample than for the AE sample. Therefore, a 1\% shock, as shown in Figure 5 , is a "smaller shock" for emerging market economies than for advanced economies. Standardizing the impulse responses such that they represent the response to a shock of one standard deviation but are expressed in terms of standard deviations of the responding variables shows that flows are more sensitive to exchange rate shocks but equally sensitive to equity shocks in the EME sample compared with the AE sample.

Figure 6 depicts how equity returns respond to a $1 \%$ shock in exchange rate returns and how exchange rate returns respond to a $1 \%$ shock in equity returns for the two samples. In the AE sample, 
Figure 6: GIRFs of EQ (FX) returns to shocks in FX (EQ) returns
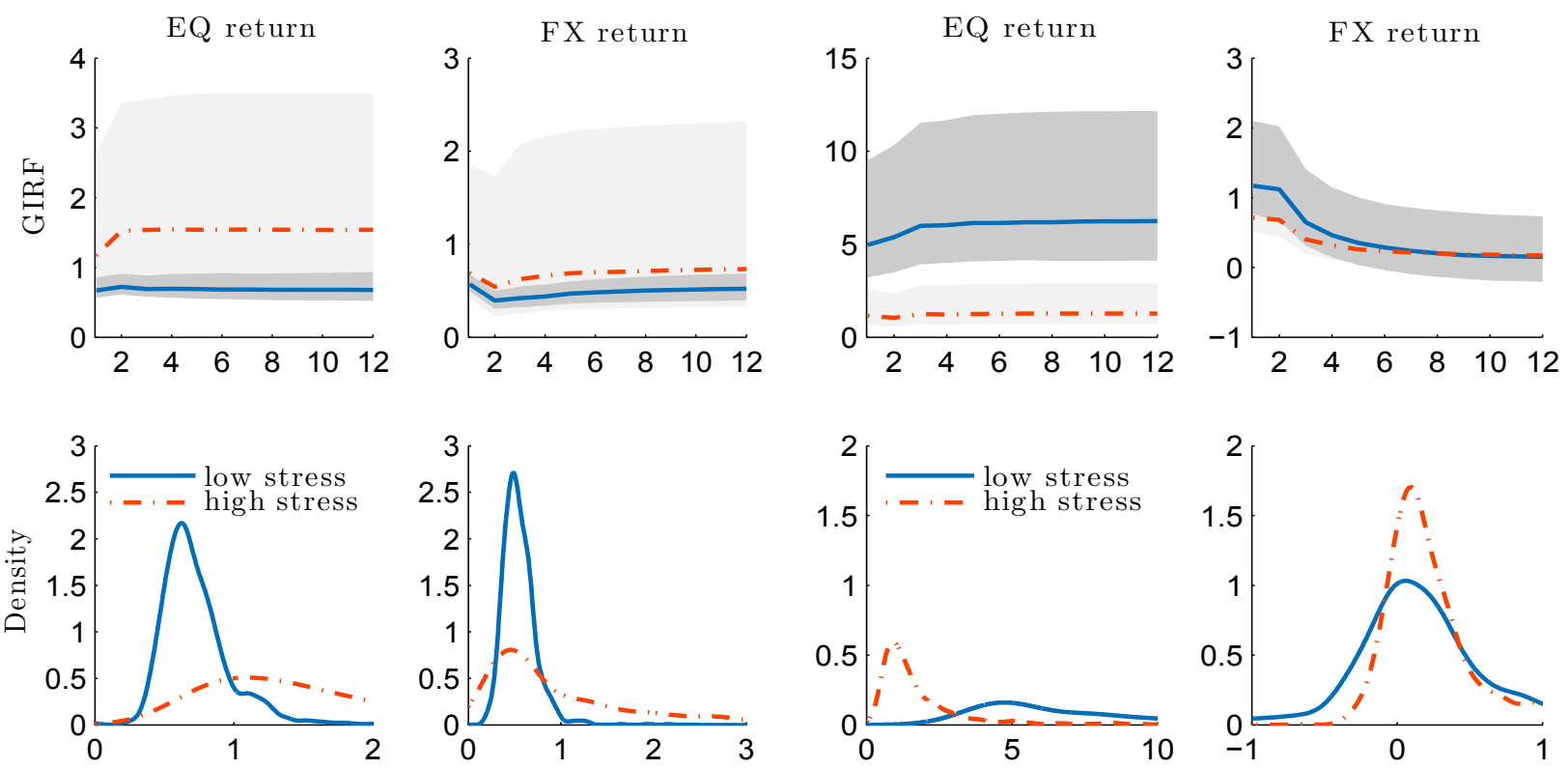

(a) Advanced Economies

(b) Emerging Market Economies

Notes: Cumulative generalized impulse responses (GIRF) of returns in the two samples. The upper row shows how equity (exchange rate) returns react to a positive shock in exchange rate (equity) returns over time. The shock is normalized so that it corresponds to a shock of one percentage point in returns. The lines correspond to the median, and the shaded areas correspond to the $68 \%$ posterior credible set. The lower row shows the posterior density of the same impulse responses after 12 months. State 1 denotes periods of low financial stress and state 2 periods of high financial stress.

reported in Panel (a), the difference in the median impulse responses is negligible, considering the disperse distributions. In contrast, Panel (b) shows that there are significant differences in the posterior distribution of responses of equity returns to a shock in exchange rate returns. The $68 \%$ credible sets of responses in the two states are distinct from each other, and the median response in the low stress state exceeds the median response in the high stress state. This statistical difference provides strong evidence that in periods of high stress, there is little transmission of exchange rate shocks to equity markets, which is in line with predictions from the theory of portfolio rebalancing. As exchange rate shocks are transmitted to equity markets through portfolio rebalancing, it directly follows that weak portfolio rebalancing will also lead to a weak transmission.

Figure 7 reports the impulse responses of equity and exchange rate returns to a shock to U.S. equity outflows. Panel (a) shows that in the AE sample, equity returns and exchange rate returns react similarly in periods of both high and low financial stress. The adjustment over time and the distribution of the responses after 12 months are comparable across the two states. Panel (b) shows only a small difference across states in the EME sample as well. Although the median response of equity returns to a flow shock is lower in the high stress state, it is still in the $68 \%$ credible set of 
Figure 7: GIRFs of equity and exchange rate returns to equity flow shocks
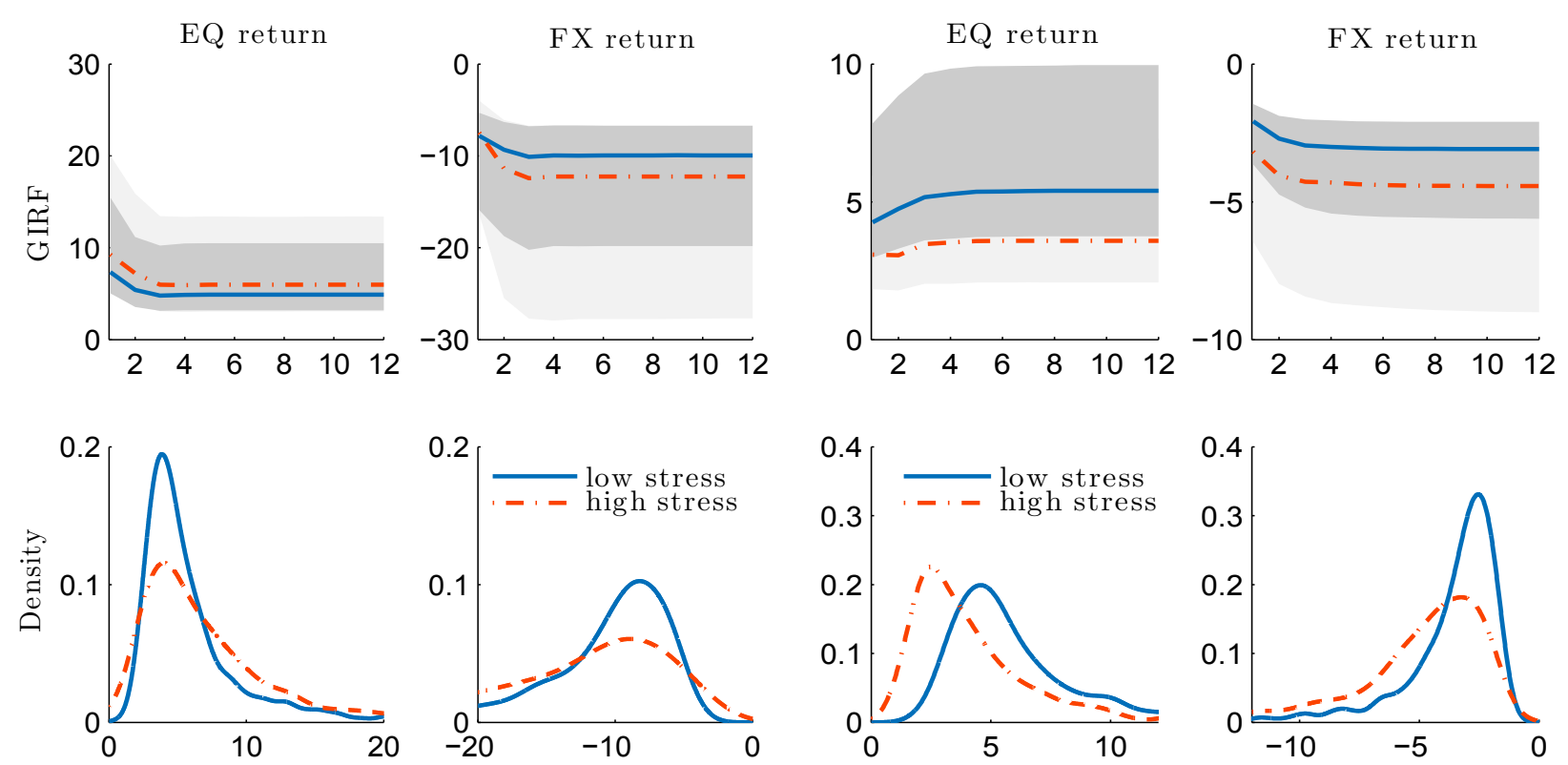

(a) Advanced Economies
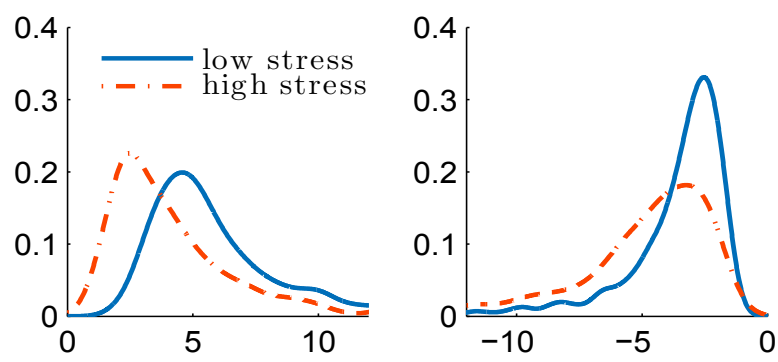

(b) Emerging Market Economies

Notes: Cumulative generalized impulse responses (GIRF) of returns in the two samples. The upper row shows how equity and FX returns react to a positive shock in net flows over time. The shock is normalized so that it corresponds to a shock of one percentage point in net flows. The lines correspond to the median, and the shaded areas correspond to the $68 \%$ posterior credible set. The lower row shows the posterior density of the same impulse responses after 12 months.

the normal state and provides no clear evidence whether equity returns react less to flow shocks in periods of high stress because of stronger liquidity constraints. For exchange rate returns, the slightly larger price effects of net flows in the "high stress" state 2 are consistent with the model of Gabaix and Maggiori (2015), but the difference across states is not statistically significant.

Forecast error variance decompositions confirm the changing strength of portfolio rebalancing in the "high stress" state 2 of the model. ${ }^{19}$ One observation from these decompositions is that in state 2 , more of the forecast error variance of each variable is explained by shocks to that variable. For example, for EMEs, EQ return shocks explain only $30 \%$ of equity return differentials in state 1 , as opposed to $50 \%$ in state 2 . In particular, for EMEs, the flow shocks explain a markedly lower fraction of the FX and EQ return forecast errors in state 2.

For EMEs, the share of EQ flow forecast error variance that is explained by FX shocks drops in state 2 compared with state 1 , which is consistent with the above finding that the impulse responses of EQ flows to FX shocks are lower in state 2. In contrast, however, EQ return shocks explain more of the EQ flow variance in state 2 than in state 1, even though the corresponding impulse response of flows to EQ return shocks is lower in state 2. This implies that while the effect of a unit EQ

\footnotetext{
${ }^{19}$ Forecast error variance decompositions are reported in Figures 10 for AEs and 11 for EMEs in Appendix C.
} 
return shock on flows is lower in state 2 , the variance of such shocks is higher.

\section{Robustness checks}

We perform several robustness checks to confirm the baseline results from the previous section. The robustness checks consider issues related to the choice of the weighting scheme, the setting of the priors, and the sample size. In each case, we find results that are in line with the findings from the baseline specification. Because of the similarity between the results from the baseline and the robustness checks, we discuss the outcomes of the robustness checks but do not reproduce the same graphs from the previous section.

\subsection{Re-weighting the AE and EME countries}

A first robustness check addresses a potential endogeneity concern arising from our weighting scheme that may put undue weight on exchange rate and equity returns when equity flows are especially high for a particular country. To address this concern, the model is re-estimated using alternative country weights for equity returns and exchange rate returns. More specifically, we use the MSCI World ex US and the MSCI Emerging markets indices for equity returns and the US Major currency and US Other important trading partner trade weighted exchange rate indices for exchange rate returns. ${ }^{20}$ Using the weights from these two sources should alleviate endogeneity concerns, since the new weights are calculated independently of equity flows. For equity flows, the weighting scheme remains the same because they are simply aggregated for the AE and EME samples.

The results from this new weighting scheme show the same pattern as the baseline results. One exception is that the distributions of the impulse responses in the AE and EME samples are now wider. In other words, the impulse responses from the two states overlap each other, and the medians from the two states lie in each other's $68 \%$ credible sets. This result can be attributed to the difference in the covered countries. The weights from the new indices cover a range of countries that are not included in our sample; thus, some weighting bias is introduced, which can lead to a wider distribution.

A second approach to address the endogeneity concern is to use constant weights throughout the sample. Such an approach reduces endogeneity issues in that it no longer puts more weight on returns for some countries in certain months. The constant weighting scheme produces results comparable to our baseline results. As in the baseline specification from the previous section, the impulses responses from the constant weighting model yield distinguishable states between the high and low financial stress regimes.

\footnotetext{
${ }^{20}$ Though the name may suggest differently, the MSCI World ex US index covers only equities from developed markets.
} 
A further weighting check is to exclude some countries from the AE and EME samples. The selection is based on considering only the 7 largest $\mathrm{AE}$ and 4 largest EME countries in terms of gross equity in- and outflows. Again, the results from the reduced country sample are consistent with our baseline results. The estimated posterior probability of the states and the estimated impulse responses match the baseline results well. Though the $68 \%$ credible sets are not completely distinct for the EME sample, the median responses of flows in high stress periods lie outside the $68 \%$ credible set of responses of the low stress periods.

\subsection{Choice of priors}

A second robustness check is to consider how the MSVAR responds to different specifications of priors. Several considerations are undertaken. The Dirichlet prior is first set more tightly. This pushes the model to find more persistent symmetric states. ${ }^{21}$ With this prior specification, the analysis of the generated posterior distribution shows that the states are not well identified. Parameter draws and thus the impulse responses are similar between the two states. This result supports our hypothesis of a highly persistent state identified as the regime of low financial stress and a low persistent state identified as the regime of high financial stress. Next, loosening the Dirichlet prior and making it symmetric does not change the baseline results.

Further checks include loosening the prior on the AR(1) coefficients of the reduced-form VAR model while keeping the other hyperparameters and the combinations of different Dirichlet and VAR hyperparameters. ${ }^{22}$ With these different specifications, the results remain consistent with the baseline specification from the previous section. This outcome confirms that our baseline results are driven by the data and not from our choice of priors. With a looser prior on the AR(1) coefficients, the results of a low level of portfolio rebalancing in high stress states are reinforced even further, as no impulse responses that fulfill our sign restrictions are found.

\subsection{Sample size}

A third robustness test restricts the sample to periods after January 2000. Using a sample beginning before 2000 may have influenced the findings because of the introduction of the euro in 1999 and because of changing monetary policy strategies in emerging market economies with respect to their national currencies after the Asian crisis between 1997 and 1998.

The results from the restricted sample are in line with the baseline results presented in the previous section. This is true for the AE and the EME samples. The second regime state matches periods of high financial stress. As in the baseline results, the response of equity returns to exchange rate shocks is lower, and there is also a statistical significant separation of the $68 \%$ credible sets in the restricted EME sample. Further, equity flows respond less to price shocks in periods of high

\footnotetext{
${ }^{21}$ In the notation of Sims, Waggoner and Zha (2008), the priors are defined as $\alpha_{11}=\alpha_{22}=12$ and $\alpha_{12}=\alpha_{21}=2$.

${ }^{22}$ The hyperparameter $\lambda_{1}$ was set to 0.9 .
} 
financial stress. Although this separation is less pronounced and the credible sets of responses in the two states coincide, the medians lie outside the credible set of the other state.

\section{Conclusions}

This paper studies time variation in the dynamics of equity returns, exchange rate returns, and international equity flows. We extend the analysis in Hau and Rey (2004) by introducing a two-state Markov regime switching model into the structural VAR. The model is estimated using monthly data for the period 1995-2015. Rather than estimating the model for bilateral capital flows, as in Hau and Rey (2004) and most related subsequent studies, we aggregate capital flows and asset returns across advanced and emerging economies. This has the advantage of reducing the biases inherent in the TIC data on international capital flows to and from the United States. To the best of our knowledge, this paper is the first to consider the changing dynamics of international portfolio rebalancing.

Our results suggest that models of portfolio rebalancing provide a good description of investor behavior for U.S. international capital flows. We also find that the estimated regimes match periods of low and high financial stress, as indicated by common risk measures. We therefore interpret the estimated regimes as reflecting low and high risk states. The empirical results for advanced economies show that the dynamics of equity returns, exchange rate returns, and equity flows are remarkably stable across periods of low and high stress. For emerging market economies, however, the stabilizing properties of portfolio rebalancing are weak in periods of high financial stress. This finding is in line with the theoretical predictions of portfolio rebalancing models, if periods of crisis are associated with increasing investor risk aversion or elevated return volatility. In addition, for emerging market economies, a switch towards a period of high financial stress is associated with equity outflows.

Our empirical findings have important policy implications for the role of equity flows in emerging market crises. Portfolio rebalancing tends to mitigate adverse shocks. For example, a negative equity return shock in emerging market economies leaves international investors holding too little emerging market equities in their portfolios, prompting equity flows into emerging market economies. These flows induce an emerging market currency appreciation and tend to dampen the equity price drop, thus mitigating the initial adverse shock. This mechanism relies on the assumptions that (1) the shock has not affected the expected returns and volatility of emerging market stocks and that (2) international investors are not completely hedged against the effects of such shocks. Our finding that rebalancing is considerably reduced in crisis periods for emerging markets implies that equity flows do not or to a lesser degree perform the stabilizing role that is implied by portfolio rebalancing models. Our findings for emerging market economies therefore support the prescriptions by Ostry et al. (2011) and Ostry et al. (2010) that countries may need to impose capital controls or other policy instruments to safeguard their financial system from capital flows in times of financial stress. 


\section{References}

[1] Ang, A., M.W. Brandt and D.F. Denison (2014), "Review of the active management of the Norwegian government pension fund global", available at https://www.nbim.no/en/ transparency/news-list/2014/review-of-the-funds-active-management/.

[2] Baumeister, C. and G. Peersman (2013), "The role of time-varying price elasticities in accounting for volatility changes in the crude oil markets", Journal of Applied Econometrics 28(7), $1087-1119$.

[3] Blake, D., B.N. Lehmann and A. Timmermann (1999), "Asset allocation dynamics and pension fund performance", Journal of Business 72(4), 429-461.

[4] Bikker, J.A., D.W.G.A. Broeders, and J. de Dreu (2010), "Stock market performance and pension fund investment policy: rebalancing, free float, or market timing?" International Journal of Central Banking 6(2), 53-79.

[5] Bohn, H. and L.L. Tesar (1996), "U.S. equity investment in foreign markets: portfolio rebalancing or return chasing", American Economic Review 86(2), 77-81.

[6] Breedon, F. and P. Vitale (2010), "An empirical study of portfolio-balance and information effects of order flow on exchange rates", Journal of International Money and Finance 29(3), $504-524$.

[7] Calvo, G. A., A. Izquierdo, and L. F. Mejia (2004), "On the empirics of sudden stops: The relevance of balance-sheet effects", NBER Working Papers 10520.

[8] Calvo, G. A. and C. Reinhart (2000), "When capital inflows come to a sudden stop: Consequences and policy options", In Kenen, P. and A. Swoboda, Reforming the International Monetary and Financial System. Washington, DC: International Monetary Fund.

[9] Calvo, A. (1998), "Capital flows and capital-market crises: The simple economics of sudden stops", Journal of Applied Economics 1(1), 35-54.

[10] Caporale, G.M., F.M. Ali and N. Spagnolo (2015), "Exchange rate uncertainty and international portfolio flows: a multivariate GARCH-in-mean approach", Journal of International Money and Finance 54, 70-92.

[11] Cogley, T. and T.J. Sargent (2005), "Drifts and volatilities: monetary policies and outcomes in the post WWII US", Review of Economic Dynamics 8(2), 262-302.

[12] Curcuru, S.E., C.P. Thomas, F.E. Warnock and J. Wongswan (2011), "US international equity investment and past and prospective returns", American Economic Review 101(7), 3440-3455. 
[13] De Haan, L. and J. Kakes (2011) "Momentum or contrarian investment strategies: evidence from Dutch institutional investors", Journal of Banking and Finance 35(9), 2245-2251.

[14] Dornbusch, R., I. Goldfajn, and R. O. Valdes (1995) "Currency crises and collapses", Brookings Papers on Economic Activity 2, 219-293.

[15] Dornbusch, R. and A. Werner (1994), "Mexico: Stabilization, reform and no growth", Brookings Papers on Economic Activity 1, 253-316.

[16] Ehlers, T. and E. Takáts (2013), "Capital flow dynamics and FX intervention", BIS Paper No 73.

[17] Ehrmann, M., M. Ellison and N. Valla (2003), "Regime-dependent impulse response functions in a Markov-switching vector autoregression model", Economics Letters 78(3), 295-299.

[18] Fecht, F. and P. Gruber (2012), "Interaction of funding liquidity and market liquidity - Evidence from the German stock market", mimeo.

[19] Forbes, K. J. and F. E. Warnock (2012), "Capital flow waves: Surges, stops, flight, and retrenchment", Journal of International Economics 88(2), 235-251.

[20] Frühwirth-Schnatter, S. (2001), "Markov chain Monte Carlo estimation of classical and dynamic switching and mixture models", Journal of the American Statistical Association 96(453), 194-209.

[21] Frühwirth-Schnatter, S. (2006), Finite mixture and Markov switching models, Springer Science \& Business Media.

[22] Gabaix, X. and M. Maggiori (2015), "International Liquidity and Exchange Rate Dynamics", Quarterly Journal of Economics 130(3), 1369-1420.

[23] Griever, W.L., G.A. Lee, F.E. Warnock and C. Cleaver (2001), "The U.S. system for measuring cross-border investment in securities: a primer with a discussion of recent developments", Federal Reserve Bulletin 87(10), 633-651.

[24] Gyntelberg, J., M. Loretan, T. Subhanij, and E. Chan (2014), "Exchange rate fluctuations and international portfolio rebalancing", Emerging Markets Review 18, 34-44.

[25] Gyntelberg, J., M. Loretan and T. Subhanij (2015), "Private information, capital flows, and exchange rates", SNB working paper 2015-12.

[26] Hau, H. and H. Rey (2004), "Can portfolio returns explain the dynamics of equity returns, equity flows, and exchange rates?", American Economic Review 94(2), 126-133. 
[27] Hau, H. and H. Rey (2006), "Exchange rates, equity prices, and capital flows", Review of Financial Studies 19(1), 273-317.

[28] Hau, H. and H. Rey (2008), "Global portfolio rebalancing under the microscope", NBER working paper 14165 .

[29] Hau, H., M. Massa and J. Peress (2010), "Do demand curves for currencies slope down? Evidence from the MSCI global index change", Review of Financial Studies 23(4), 473-490.

[30] Hutchison, M. M. and I. Noy (2006), "Sudden stops and the Mexican wave: Currency crises, capital flow reversals and output loss in emerging markets", Journal of Development Economics $79(1), 225-248$.

[31] Krolzig, H. (2006), "Impulse response analysis in Markov switching vector autoregressive models." Keynes College: Economics Department, University of Kent.

[32] Nyborg, K. G. and P. Östberg (2014), "Money and liquidity in financial markets", Journal of Financial Economics 112(1), 30-52.

[33] Ostry, J. D., A. R. Ghosh, K. Habermeier, L. Laeven, M. Chamon, M. S. Qureshi, and A. Kokenyne (2011), "Managing Capital Inflows: What Tools to Use?", IMF Staff Discussion Note, 5 April.

[34] Ostry, J. D., A. R. Ghosh, K. Habermeier, M. Chamon, M. S. Qureshi, and D. B.S. Reinhardt (2010), "Capital Inflows: The Role of Controls", IMF Position Note, 19 February.

[35] Primiceri, G.E. (2005), "Time varying structural vector autoregressions and moentary policy", Review of Economic Studies 72(3), 821-852.

[36] Rauh, J.D. (2009), "Risk shifting versus risk management: investment policy in corporate pension plans", Review of Financial Studies 22(7), 2687-2733.

[37] Reinhart, C. and V. Reinhart (2009), "Capital flow bonanzas: An encompassing view of the past and present", NBER Chapters, in: NBER International Seminar on Macroeconomics 2008, pages 9-62 National Bureau of Economic Research, Inc.

[38] Rubio-Ramirez, J. F., D. F. Waggoner and T. Zha (2010), "Structural vector autoregressions: Theory of identification and algorithms for inference", Review of Economic Studies 77(2), $665-696$.

[39] Sims, C.A. and T. Zha (1998), "Bayesian methods for dynamic multivariate models", International Economic Review 39(4), 949-968. 
[40] Sims, C. A., D. F. Waggoner and T. Zha (2008), "Methods for inference in large multipleequation Markov-switching models", Journal of Econometrics 146(2), 255-274. 


\section{Appendix}

\section{A Generalized impulse responses}

Let $I R F_{j, t}$ be the stacked impulse responses of different variables $i$ as defined in equation (5). Using the reduced form model described in equation (4), the impulse responses on the effect to a shock in variable $j$ in state $s$ can be calculated as follows:

$$
\begin{gathered}
I R F_{j, t}=B_{s} X_{t}+A_{0, s}^{-1} \epsilon_{t, j}-B_{s} X_{t} \\
=A_{0, s}^{-1} \epsilon_{t, j}
\end{gathered}
$$

For periods after the effect, the system is allowed to switch between states. Consequently, the switching probabilities need to be included when calculating the conditional expectations. The $k$-period ahead impulse response is calculated as:

$$
I R F_{j, t+k}=\Sigma_{l=1}^{2} \mathbb{P}\left(s_{t+2}=l \mid s_{t}=s\right) B_{l}\left[\begin{array}{c}
I R F_{j, t+k-1} \\
I R F_{j, t+k-2} \\
0
\end{array}\right]
$$

Gathering the state probabilities in:

$$
Q=\left[\begin{array}{ll}
P\left(s_{t+1}=1 \mid s_{t}=1\right) & P\left(s_{t+1}=2 \mid s_{t}=1\right) \\
P\left(s_{t+1}=1 \mid s_{t}=2\right) & P\left(s_{t+1}=2 \mid s_{t}=2\right)
\end{array}\right]
$$

allows us to get $\mathbb{P}\left(s_{t+k}=i \mid s_{t}=j\right)$ as the $i$ th column and the $j$ th row from the matrix $Q^{k}$. Thus:

$$
I R F_{j, t+k}=\Sigma_{l=1}^{2}\left[Q^{k}\right]_{l} B_{l}\left[\begin{array}{c}
I R F_{j, t+k-1} \\
I R F_{j, t+k-2} \\
0
\end{array}\right]
$$




\section{B Responses to a regime switch}

Let $I R F_{s h, t+k}$ be the stacked responses of different variables $i$ to a switch from regime $s$ to regime $h$ in period $t$ as defined in equation (7). Using the reduced form model described in equation (4), it can be calculated for period $t$ as follows:

$$
\begin{aligned}
I R F_{s h, t}= & B_{1, h} y_{t-1}+B_{2, h} y_{t-2}+c_{h}-B_{1, s} y_{t-1}-B_{2, s} y_{t-2}-c_{s} \\
& =B_{h}\left[\begin{array}{c}
y_{t-1} \\
y_{t-2} \\
1
\end{array}\right]-B_{s}\left[\begin{array}{c}
y_{t-1} \\
y_{t-2} \\
1
\end{array}\right]=\left[B_{h}-B_{s}\right] X_{t}
\end{aligned}
$$

To simplify the notation, let $\mathbb{E}[Z \mid s] \equiv \mathbb{E}\left[Z \mid s_{t}=h, X_{t}\right]$. Then, the $k$-period ahead response to a switch from regime $s$ to regime $h$ is calculated as:

$$
\begin{aligned}
I R F_{s h, t+k}= & \mathbb{E}\left[y_{t+k} \mid s_{t}=h, X_{t}\right]-\mathbb{E}\left[y_{t+k} \mid s_{t}=s, X_{t}\right] \\
= & \sum_{l=1}^{2}\left(\left[Q^{k}\right]_{h l} B_{1, l}\right) \mathbb{E}\left[y_{t+k-1} \mid h\right]+\sum_{l=1}^{2}\left(\left[Q^{k}\right]_{h l} B_{2, l}\right) \mathbb{E}\left[y_{t+k-2} \mid h\right] \\
& -\sum_{l=1}^{2}\left(\left[Q^{k}\right]_{s l} B_{1, l}\right) \mathbb{E}\left[y_{t+k-1} \mid s\right]-\sum_{l=1}^{2}\left(\left[Q^{k}\right]_{s l} B_{2, l}\right) \mathbb{E}\left[y_{t+k-2} \mid s\right] \\
& +\sum_{l=1}^{2}\left(\left[\left[Q^{k}\right]_{h l}-\left[Q^{k}\right]_{s l}\right] C_{l}\right) \\
= & \sum_{l=1}^{2}\left(\left[Q^{k}\right]_{h l} B_{l}\right)\left[\begin{array}{c}
\mathbb{E}\left[y_{t+k-1} \mid h\right] \\
\mathbb{E}\left[y_{t+k-2} \mid h\right] \\
1
\end{array}\right]-\sum_{l=1}^{2}\left(\left[Q^{k}\right]_{s l} B_{l}\right)\left[\begin{array}{c}
\mathbb{E}\left[y_{t+k-1} \mid s\right] \\
\mathbb{E}\left[y_{t+k-2} \mid s\right] \\
1
\end{array}\right]
\end{aligned}
$$

where the state probabilities are gathered in $Q$ as shown for the calculations of the generalized impulse responses. 


\section{Additional figures and tables}

Figure 8: GIRFs Advanced Economies
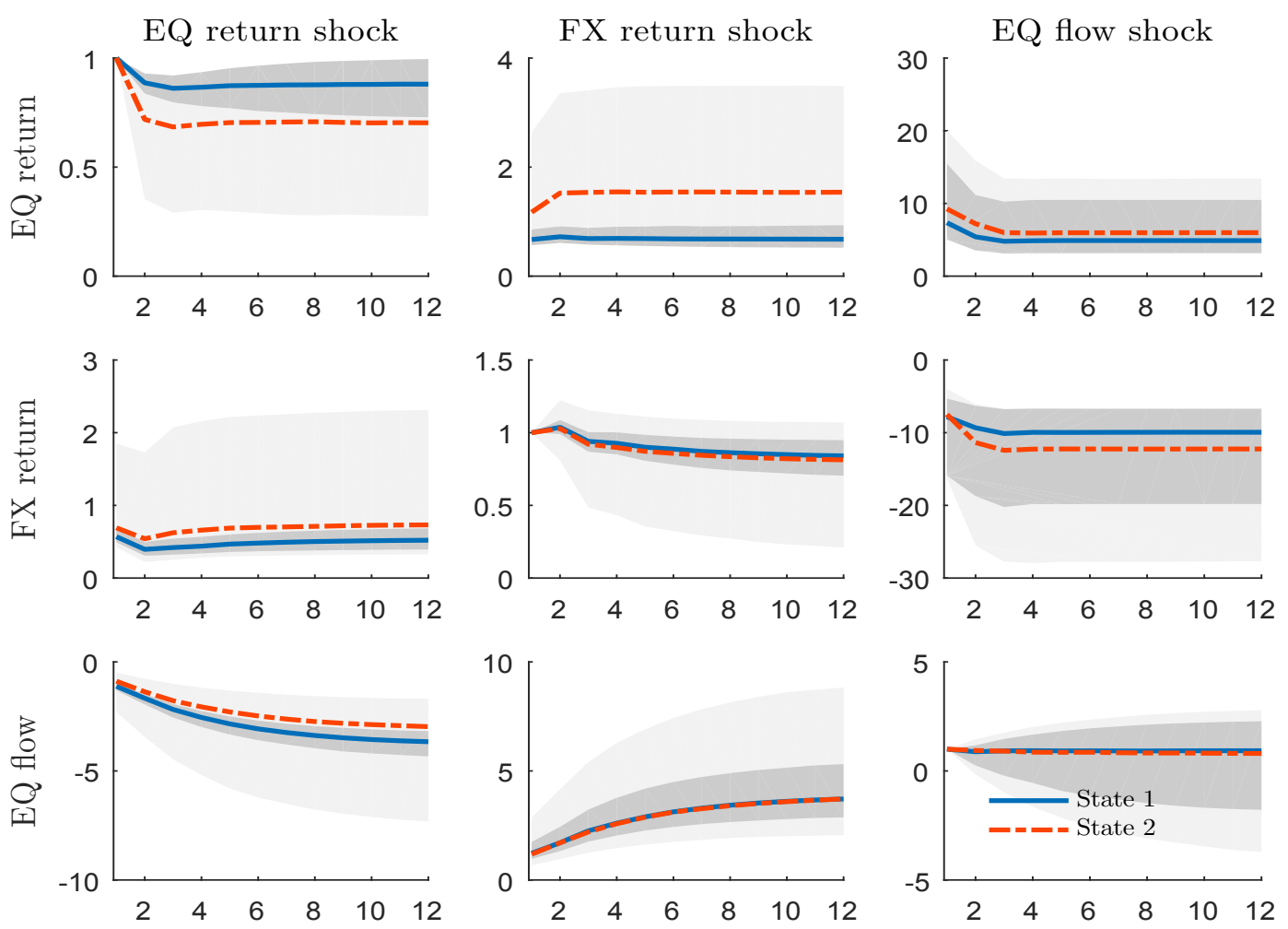

Notes: Cumulative generalized impulse responses in the two states of variables listed in rows to shocks listed the columns. The shocks are normalized so that they correspond to a shock of one percentage point in the respective variable. Solid lines indicate the median, and shaded areas indicate the $68 \%$ credible set of models that satisfy the sign restrictions. 
Figure 9: GIRFs Emerging Markets
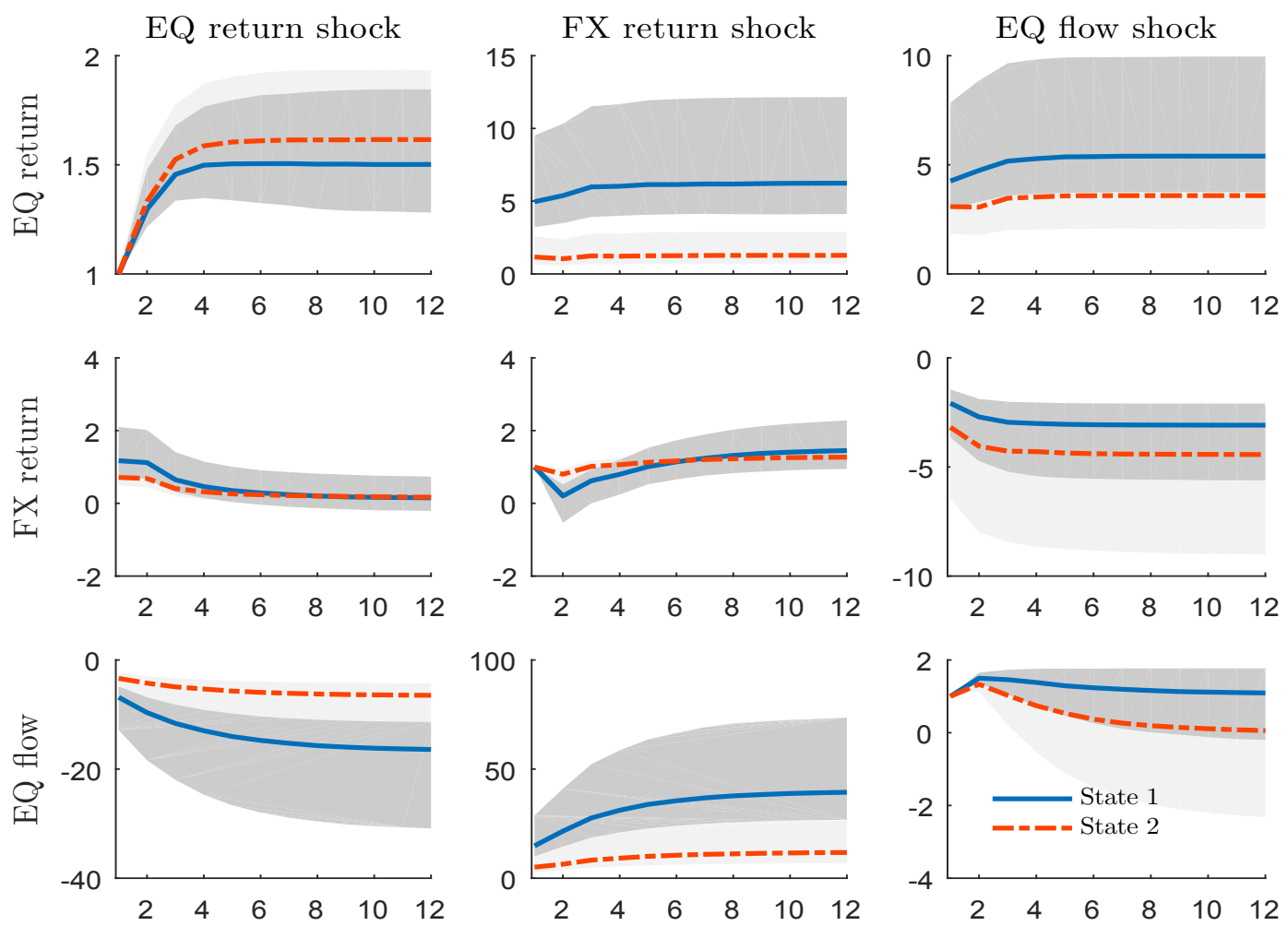

Notes: Cumulative generalized impulse responses of variables listed in rows to shocks listed the columns. The shocks are normalized so that they correspond to a shock of one percentage point in the respective variable. Lines indicate the median, and shaded areas indicate the $68 \%$ credible set of the distribution across models that satisfy the sign restrictions. 
Figure 10: FEVD Advanced Economies
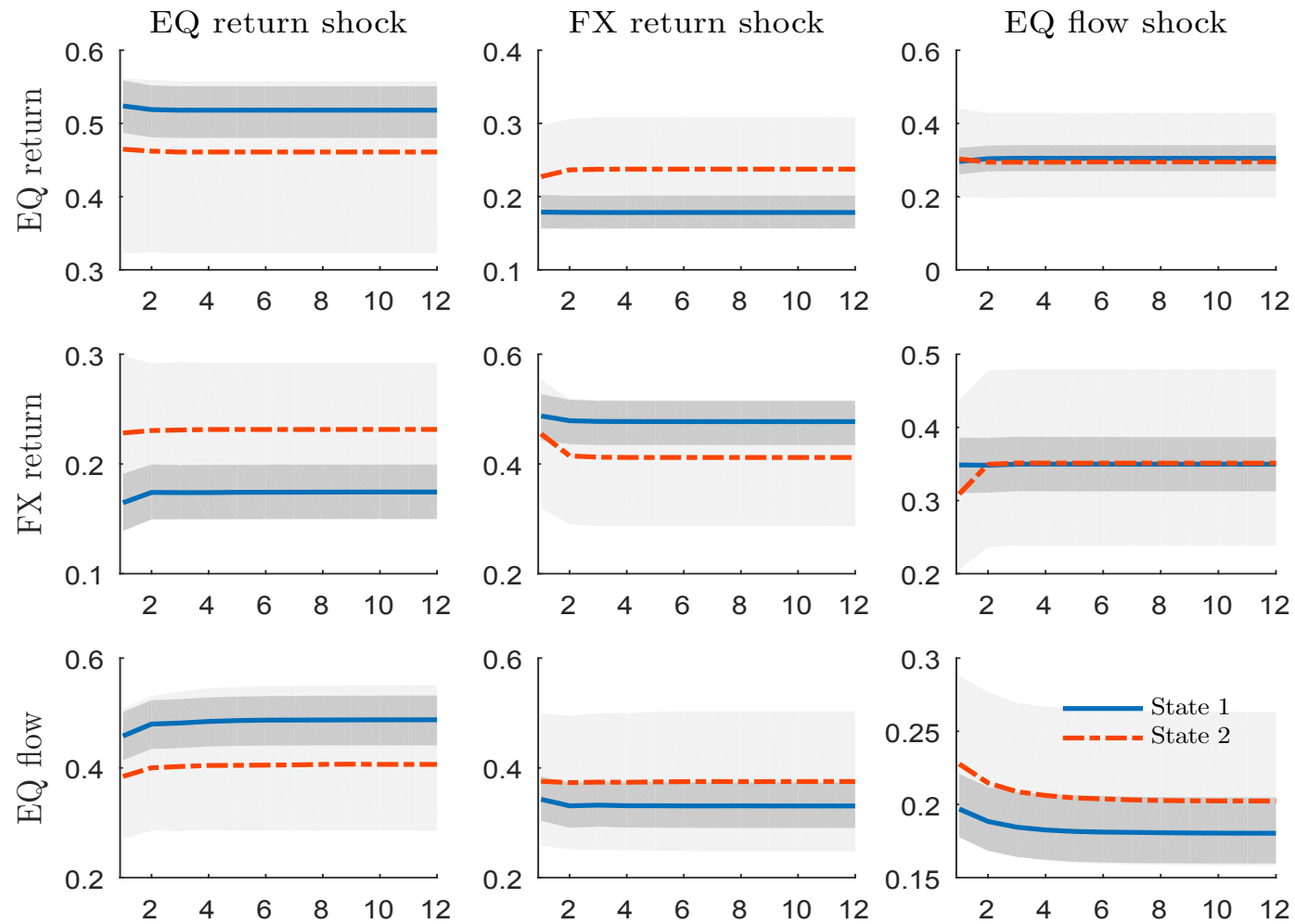

Notes: Forecast error variance decomposition (FEVD) in the two states: share of the forecast error variance of variables listed in rows, explained by shocks listed the columns. Solid lines indicate the median, and shaded areas indicate the $68 \%$ credible set of models that satisfy the sign restrictions. 
Figure 11: FEVD Emerging Markets
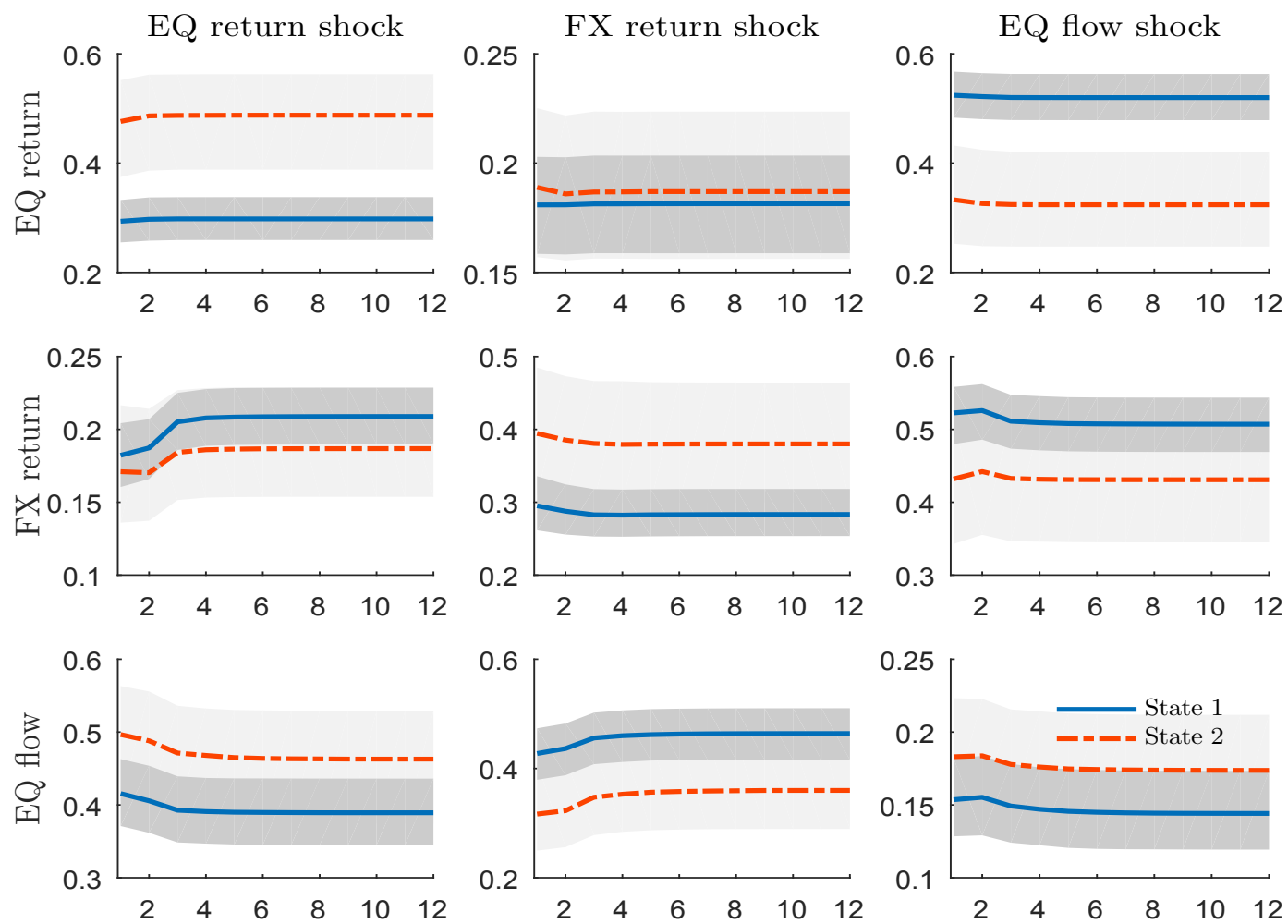

Notes: Forecast error variance decomposition (FEVD) in the two states: share of the forecast error variance of variables listed in rows, explained by shocks listed the columns. Solid lines indicate the median, and shaded areas indicate the $68 \%$ credible set of models that satisfy the sign restrictions. 
Table 3: Countries

\begin{tabular}{llr} 
Country & MSCI index ticker & Currency ticker \\
\hline Advanced Economies: & & \\
Australia & & \\
Austria & MSAUSTL & MSERAUD \\
Belgium & MSASTRL & MSEREUR \\
Canada & MSBELGL & MSEREUR \\
Denmark & MSCNDAL & MSERCAD \\
Finland & MSDNMKL & MSERDKK \\
France & MSFINDL & MSEREUR \\
Germany & MSFRNCLY & MSEREUR \\
Greece & MSGERML & MSEREUR \\
Ireland & MSGREEL & MSEREUR \\
Italy & MSEIREL & MSEREUR \\
Japan & MSITALL & MSEREUR \\
Netherlands & MSJPANL & MSERJPY \\
Norway & MSNETHL & MSEREUR \\
Portugal & MSNWAYL & MSERNOK \\
Spain & MSPORDL & MSEREUR \\
Sweden & MSSPANL & MSEREUR \\
Switzerland & MSSWDNL & MSERSEK \\
United Kingdom & MSSWITL & MSERCHF \\
& MSUTDKL & MSERGBP \\
Em. Market Economies: & & \\
Brazil & & \\
Chile & MSBRAZL & MSERBRL \\
Colombia & MSCHILL & MSERCLP \\
Czech Republic & MSCOLML & MSERCOP \\
Hungary & MSCZCHL & MSERCZK \\
India & MSHUNGL & MSERHUF \\
Indonesia & MSINDIL & MSERINR \\
Israel & MSINDFL & MSERIDR \\
Mexico & MSISRLL & MSERILS \\
Poland & MSMEXFL & MSERTWD \\
South Africa & MSPLNDL \\
South Korea & MSSARFL \\
Taiwan & MSKOREL & MSTHIHL \\
Thailand & & \\
\hline \hline & & \\
\hline
\end{tabular}

Notes: The EUR series has been extended back to 1995 using the series EUDOLLR from Datastream. 


\section{Recent SNB Working Papers}

2017-11 Andreas M. Fischer, Rafael Greminger and Christian Grisse: Portfolio rebalancing in times of stress.

2017-10 Christian Grisse and Silvio Schumacher: The response of long-term yields to negative interest rates: evidence from Switzerland.

2017-9 Petra Gerlach-Kristen, Richhild Moessner and Rina Rosenblatt-Wisch: Computing long-term market inflation expectations for countries without inflation expectation markets.

2017-8 Alain Galli: Which indicators matter? Analyzing the Swiss business cycle using a large-scale mixedfrequency dynamic factor model.

2017-7 Gregor Bäurle, Matthias Gubler and Diego R. Känzig: International inflation spillovers - the role of different shocks.

2017-6 Lucas Marc Fuhrer: Liquidity in the Repo Market.

2017-5 Christian Grisse, Signe Krogstrup and Silvio Schumacher: Lower bound beliefs and long-term interest rates.

2017-4 Toni Beutler, Robert Bichsel, Adrian Bruhin and Jayson Danton: The Impact of Interest Rate Risk on Bank Lending.

2017-3 Raphael A. Auer, Andrei A. Levchenko and Philip Sauré: International Inflation Spillovers Through Input Linkages.

2017-2 Alain Galli, Christian Hepenstrick and Rolf Scheufele: Mixed-frequency models for tracking short-term economic developments in Switzerland.
2017-1 Matthias Gubler and Christoph Sax: The Balassa-Samuelson Effect Reversed: New Evidence from OECD Countries.

2016-19 Jens H.E. Christensen and Signe Krogstrup: A Portfolio Model of Quantitative Easing.

2016-18 Jonas Meuli, Thomas Nellen and Thomas Nitschka: Securitisation, loan growth and bank funding: the Swiss experience since 1932 .

2016-17 Rita Fleer, Barbara Rudolf and Mathias Zurlinden: Price change dispersion and time-varying pass-through to consumer prices.

2016-16 Gregor Bäurle, Daniel Kaufmann, Sylvia Kaufmann and Rodney W. Strachan: Changing dynamics at the zero lower bound.

2016-15 Adrian Jäggi, Martin Schlegel and Attilio Zanetti: Macroeconomic surprises, market environment and safe-haven currencies.

2016-14 Alain Galli: Sticky consumption and wealth effects in Switzerland.

2016-13 Gregor Bäurle and Rolf Scheufele: Credit cycles and real activity - the Swiss case.

2016-12 Silvio Schumacher: Networks and lending conditions: Empirical evidence from the Swiss franc money markets.

2016-11 Lucas Marc Fuhrer, Benjamin Müller and Luzian Steiner: The Liquidity Coverage Ratio and Security Prices. 
